Chapter 8

\title{
Modeling Issues of Grid-Integrated Wind Farms for Power System Stability Studies
}

\author{
Tamer A. Kawady and Ahmed M. Nahhas \\ Additional information is available at the end of the chapter \\ http://dx.doi.org/10.5772/54612
}

\section{Introduction}

Owing to the rapid increase of the global population, uneven distribution of resources and the non-renewable nature of fossil fuels, the importance of renewable energy resources is obvious. Further, growing environmental concerns and attempts to reduce dependency on fossil fuel resources are bringing renewable energy resources to the mainstream of the electric power sector. Among the various renewable resources, wind power is assumed to have the most favourable, technical and economical prospects. According to the new energy policies regarding the share of renewable energy by 2020, different countries all over the world have their own targets. Examples of these countries with their penetration levels included Denmark (52\%), Sweden (50\%), Spain (41\%) Germany (39\%) and Finland (38\%). Accordingly, realizing an accurate representation of such power plants and their remarkable issues regarding their integration to the power system is highly demanded.

According to the annual report of the Global Wind Energy Council (GWEC), over 40 GW of new wind power generation capacity came on line worldwide in 2011 attracting more than $\$ 68$ billions [1]. This brings the total global wind power capacity to over $238 \mathrm{GW}$ through the end of 2011 as shown in Fig. 1. This indicates that there is huge and growing global demand for emissions-free wind power which can be installed quickly and virtually everywhere in the world.

Wind power is usually extracted by wind turbines using either fixed speed or variable speed regimes. The latter is distinctive with getting more energy for a specific wind speed, better aerodynamic efficiency, less mechanical stresses and reduced noise levels. Among of these types, DFIGs represent nowadays the most preferred topology for recent wind farms. The concept of DFIG for variable-speed wind turbine provides the possibility of controlling the active and reactive power, which is significant for grid integration purposes. On the other 
hand, vector control of the DFIG enables the decoupling between active and reactive power as well as between the torque and the power factor. Hence, unique features of grid supporting are expected. The theoretical background for modeling induction machines is widely developed and is exhaustively dealt with numerous papers and textbooks as seen in the literatures. On the other hand, most of these literatures concerned mainly similar methodologies to the corresponding conventional synchronous ones for acquiring stability studies. However, the dynamic response characteristics of wind turbine generators with either fixed or variable speed operation are different from those conventional synchronous ones. This is mainly due to their operation topologies with their complex power electronics and power exchanges policies. Also, following the requirements for modern grid codes raise extra complexities and various operation modes. These concerns should be considered in order to realize a close behavior of the developed models to the realized ones in the real field. The aim of this chapter is to emphasize the essential requirements for realizing an accurate modeling of grid integrated wind farms for those purposes regarding stability studies. Detailed operation modes of the both SFIG and DFIG generators are explored. Varieties of operation modes of the DFIG one, in particular, are considered including the control of both Rotor Side Converter (RSC) and Grid Side Converter (GSC). Modern rotor protection scenarios are included using either crowbar or chopper circuitries. Moreover, the regulation of recent grid codes are followed. This results in a complete and sophisticated dynamic modeling of wind power plants integrated into grid systems. Different simulation examples are presented using the MATLAB/Simulink as a powerful tool for performing efficient dynamic modeling of complicated power systems. Some simulation examples are presented to corroborate the efficacy of the developed simulation for power system stability studies.

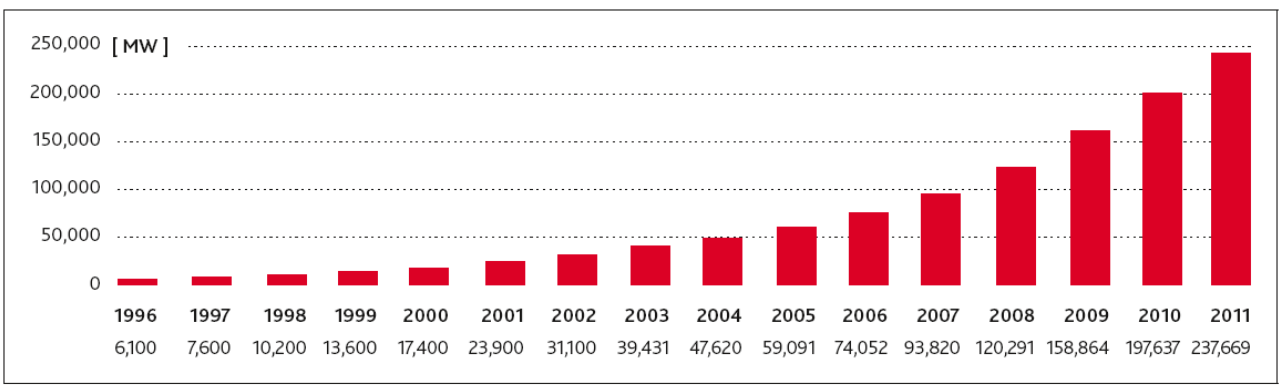

Source: CWEC

Figure 1. Global cumulative installed capacity 1996-2011 (source: GWEC annual report)

\section{Wind power plant description}

Historically, wind energy had been deployed in small scale and the integration had been carried out at the distribution system level. In this case, the impact of wind turbines generators 
on power system performance is minimal. In contrast, increasing penetration of wind power plants results in new and different kind of problems than those have been experienced in conventional grids. These problems may be owing to the random nature of the wind and the dynamic characteristics of the wind generators themselves. Fig. 2 shows a schematic diagram of a typical wind farm consisting of (n) units of wind turbines. Nowadays, modern wind farms include 20 to 150 units with typical size from $1.5 \mathrm{MW}$ to $5.0 \mathrm{MW}$ wind turbine generators. Larger sizes up to 7.0 MW are recently available in the market, and they were successfully installed in some European countries. The typical generator's terminal voltage may range from 575 to $690 \mathrm{~V}$ with frequency of 50 (or 60) Hz. The generator terminal voltage is stepped up to the Collector Bus system with typical voltage of $22-34.5 \mathrm{kV}$. The step up transformer is an oil cooled, pad mounted located at the base of the wind turbine unit. Sometimes, the step up transformer is mounted in the turbine nacelle. The typical wind farm collector system consists of a 22-34.5 distribution substation collecting the output of the distributed wind turbine generators through the incoming feeders. Finally, the collected power is transferred to the utility side via an interconnection step up transformer. Usually some reactive power compensation units are provided by a collection of switched capacitors, in addition, certain considerations should be applied for avoiding the harmonic effects [2]. The common type of the wind turbine generators that are commercially available nowadays are induction generator (IG), wound rotor synchronous generator (WRSG), and permanent magnet synchronous generator (PMSG). Due the uncontrollable natural characteristic of wind speed, the induction generators IGs are suitable for driving the wind turbines. The two basic types of wind turbines used nowadays are fixed-speed wind turbine (FSWT) that equipped with squirrel cage SFIGs and variable-speed wind turbines (VSWT) equipped with DFIGs. It is to be noted that, squirrelcage induction generators work normally within a limited wind speed range, which is one of their main drawbacks in comparison with variable-speed ones. Variable-speed wind turbines are mainly equipped with variable frequency excitation of the rotor circuit, through a partial scale back-to-back converter, whereas the stator windings are connected directly to the AC grid. The main advantage of DFIG wind turbines is their ability to supply power at a constant voltage and frequency while variations of the rotor speed [3]-[6].

Numerous wind turbines are grouped and installed into arrays at one site to build a wind farm of the desired power production capacity. The turbines may be grouped into arrays, feeding power to a utility, with its own transformers, transmission lines and substations. Stand-alone systems catering the needs of smaller communities are also common. A schematic of a typical wind farm consisting of (n) units of wind turbines is demonstrated in Fig. 3. The use of DFIGs in wind farm installations is today a standard practice, due to its suitable characteristics for the wind turbines. Certain considerations should be applied for avoiding the harmonic effects. The typical wind farm collector system consists of a distribution substation collecting the output of the distributed wind turbine generators through the incoming feeders. Usually some reactive power compensation units are provided by a collection of switched capacitors. Finally, the collected power is transferred to the utility side via an interconnection step up transformer. Further details are available in [7]. 


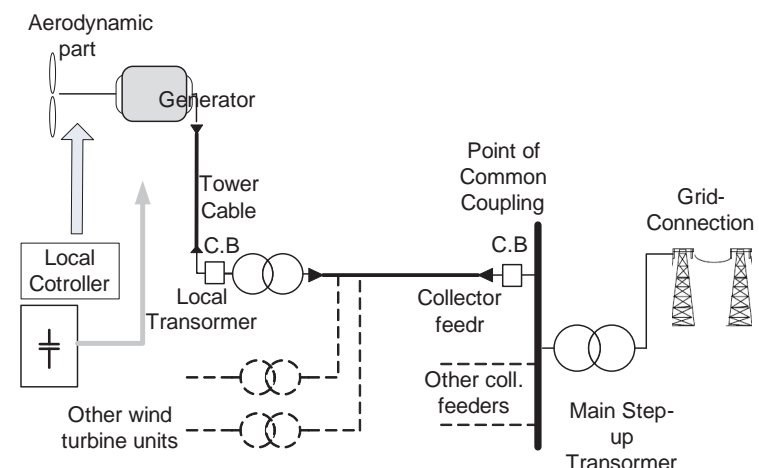

Figure 2. General schematic of a wind farm

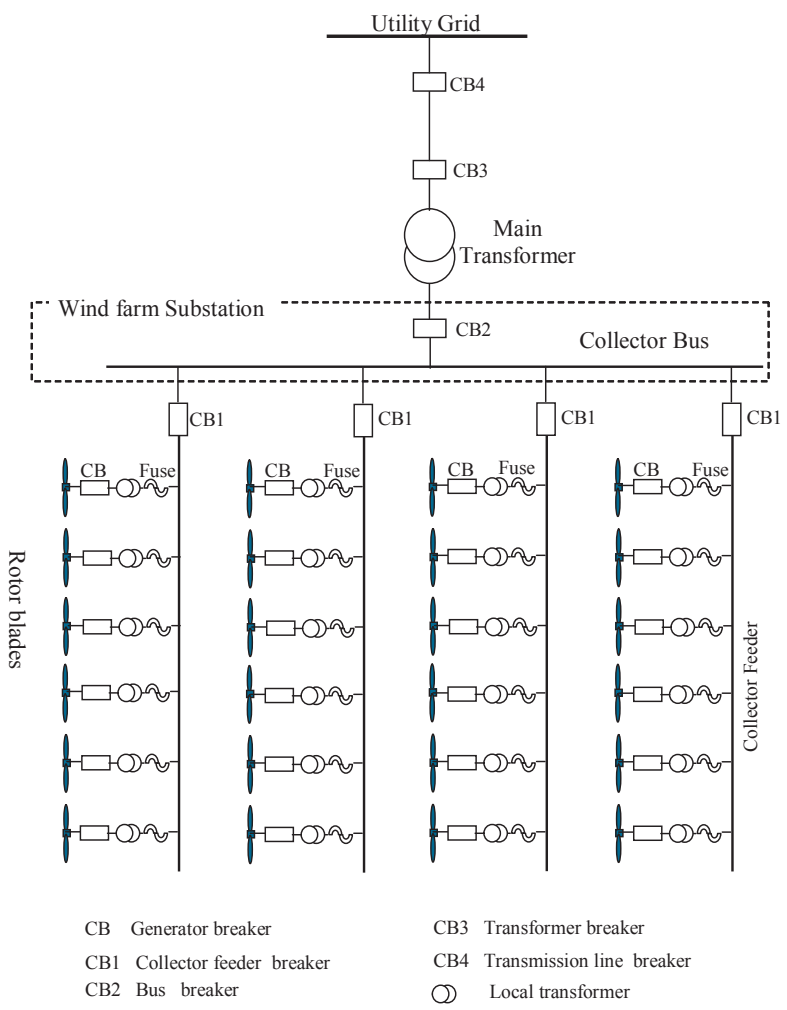

Figure 3. Principle layout of a typical wind farm system. 


\section{Power system stability overview}

"Power system stability" can be generally defined for a power system as, its ability to remain in operation equilibrium under normal operating conditions and to regain an acceptable state of equilibrium after subjecting to a disturbance. Following a large disturbance, if the power system is stable, it will reach a new equilibrium state with practically the entire system intact; the actions of automatic controls and possibly human operators will eventually restore the system to normal state. On the other hand, if the system is unstable, it will result in a run-away or run-down situation, or equivalently a progressive increase in angular separation of generator rotors, or a progressive decrease in bus voltages [8].

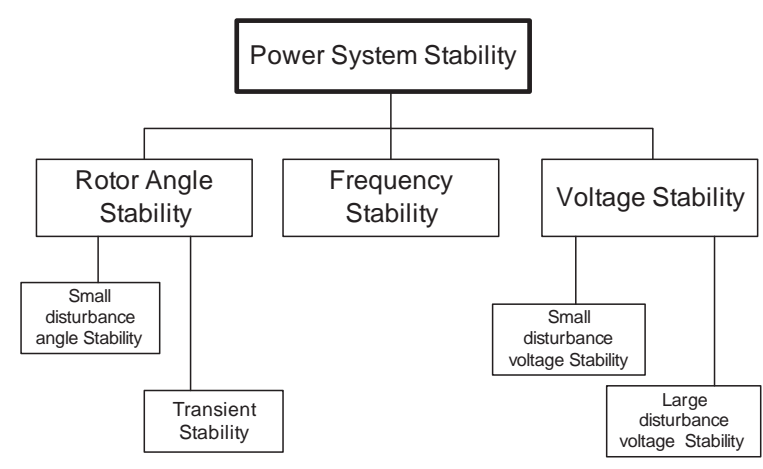

Figure 4. Classification of power system stability

From the point of view of defining and classifying power system stability, there are three important quantities for its operation; angles of nodal voltages, nodal voltage magnitudes, and system frequency. Referring to Fig. 4, the power system stability can be classified into: rotor (or power) angle stability; (ii) frequency stability; and (iii) voltage stability. Hence, different viewpoints are introduced concerning the stability issues raising different types of stability problems including "Rotor angle stability", "Frequency stability" and "Voltage stability". Rotor angle stability is concerned with the system ability to maintain the equilibrium between electromagnetic torque and mechanical torque of each generator in the system. Instability that may result occurs in the form of increasing angular swings of some generators leading to their loss of synchronism with other generators [9]-[12].

Voltage stability is concerned with the ability of a power system to maintain its steady voltage at all buses in the system under normal operating conditions, and after subjecting to a disturbance. Instability that may result occurs in the form of a progressive fall or rise of voltage of some buses. The possible outcome of voltage instability is loss of load in the area where voltages reach unacceptably low values, or a loss of integrity of the power system. The main factor contributing to voltage instability is usually the voltage drop that occurs when active and reactive power flow through inductive reactances associated with the transmission 
network. This limits the capability of transmission network for power transfer. The power transfer limit is further limited when some of the generators hit their reactive power capability limits. While the most common form of voltage instability is the progressive drop in bus voltages, the possibility of over-voltage instability also may exist and has been experienced at least on one system. It can occur when EHV transmission lines are loaded significantly below surge impedance loading and under-excitation limiters prevent generators and/or synchronous condensers from absorbing the excess reactive power. Under such conditions, transformer tap changers, in their attempt to control load voltage, may cause voltage instability [12]. Frequency stability is concerned with the ability of a power system to maintain steady frequency within a nominal range following a severe system upset, which result in a significant imbalance between generation and load. It depends on the ability to restore balance between system generation and load, with minimum loss of load. It is of importance to note that, severe system upsets generally result in large excursions of frequency, power flows, voltage, and other system variables.

Since the power system is a highly non-linear system, its stability cannot be analyzed as a single problem, and different aspects should be considered to realize reasonable conclusions. On the other hand, the response of the relevant protective elements and their response times can directly affect the stability profile of the system. This complicates the overall stability problem remarkably. Power system transient stability is defined as its ability to maintain its equilibrium state after subjecting to a severe disturbance, such as, short circuit faults.

Due to the non-linearity of power systems, their stability depends on both the initial conditions and the size of a disturbance. Consequently, angle and voltage stability are divided into smalland large-disturbance stability. "Small signal stability" is the ability of the power system to restore its equilibrium state under small disturbances. Such disturbances occur continually due to a loading, or generation, small variations. It is worthy to note that, the classification of power system stability has been based on several considerations to make it convenient for identification of the causes of instability, the application of suitable analysis tools, and the development of corrective measures appropriate for a specific stability problem. Clearly, there is some overlap between the various forms of instability, since as systems fail, more than one form of instability may ultimately emerge. However, a system event should be classified based primarily on the dominant initiating phenomenon, separated into those related primarily with voltage, rotor angle, or frequency. While classification of power system stability is an effective and convenient means to deal with the complexities of the problem, the overall stability of the system should always be kept in mind, and solution of one category should not be at the expense of another.

On the other hand, the wind farm connectivity and the random behavior of wind profile play a major role for characterizing the contribution of wind power plants during faults. Thus the behavior of fault current distribution and consequently the reaction of the protective scheme are obviously affected. moreover, the own dynamic behavior of the induction generator differs remarkably as compared with conventional synchronous ones [13], [14]. Moreover, the continuous wind speed variations and the interaction of the associated power electronics (for DFIG ones) collaborate together for providing the behavior of these machines during fault 
periods. More sophisticated and well coordinated relaying schemes should be provided to realize the most appropriate protection methodology for wind farm elements [15]-[21]. Insufficient protective elements, non-integrated control scenarios and improper coordination among protective and control strategies may lead to serious problems for large grid-connected wind farms [22]-[27]. As example for these problems is the accident happening in North Germany on November 4, 2006. The UCTA interconnected grid was affected by a serious incident originating from the North German transmission grid that led to power supply disruption for more than 15 million households, splitting a synchronously connected network into three islands (two under-frequency and one over-frequency). After cascading overloads and tripping, two of three large separated systems (Western Island and North-Eastern Island) ended up with a significant amount of wind generation resources. Western Island (underfrequency state): During the incident, about $40 \%$ of the wind power units tripped. Moreover, $60 \%$ of the wind power units connected to the grid tripped just after the frequency drop $(4,142$ MW). Wind power units were automatically reconnected to the grid when the conditions of voltage and frequency were in the accepted range. North-Eastern Island (over-frequency state): Significant imbalance in this subsystem caused rapid frequency increase and triggered the necessary primary, standard and emergency control actions of tripping wind generation units sensitive to high frequency values. Tripping these units (estimated value of 6,200 MW) helped to decrease the frequency value during the first few seconds of disturbance [28].

On the other hand, accurate wind resource assessment is essential for realizing a honest profiling of wind energy possibilities aiming to have a successful application of wind resources. As known, an error of $1 \%$ in wind speed measurements leads to almost $2 \%$ error in energy output [29]-[31]. Thus the importance of such assessment method is essential. Moreover, wind resources are seldom consistent and vary with time of the day, season of the year, height above the ground, type of terrain and from year to year. As such it should be investigated carefully and completely.

\section{Wind farm modeling for stability studies}

\subsection{SFIG wind generator modeling}

\subsubsection{Induction generator modelling}

The squirrel cage induction generator was represented as an asynchronous machine assigned with a negative mechanical torque. Fig. 5 shows the one line diagram of the implemented " $d$ " and "q" equivalent circuits in MATLAB. The electrical part of the machine model was described with a forth-order state space model, whereas its mechanical part was described with a second-order representation. Both representations were mathematically described by the following equations, where the indices $(s, r)$ were assigned for machine stator and rotor respectively. Detailed explanation of this model was clearly outlined in [32]-[35]. 


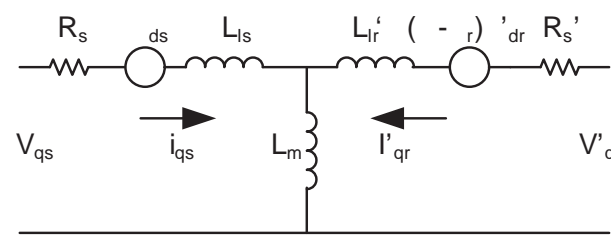

(a)

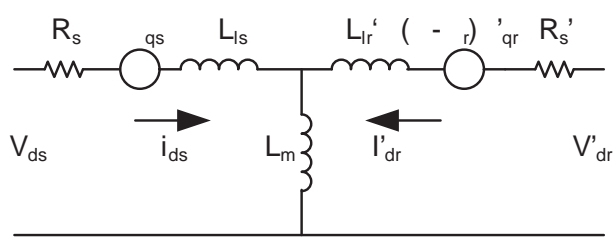

(b)

Figure 5. Equivalent circuit of MATLAB-based asynchronous machine a) q-axis equivalent. (b) d-axis equivalent

$$
\begin{aligned}
& \mathrm{V}_{\mathrm{qs}}=\mathrm{R}_{\mathrm{s}} \mathrm{i}_{\mathrm{qs}}+\frac{\mathrm{d}}{\mathrm{dt}} \varphi_{\mathrm{qs}}+\omega \varphi_{\mathrm{ds}} \\
& \mathrm{V}_{\mathrm{ds}}=\mathrm{R}_{\mathrm{s}} \mathrm{i}_{\mathrm{ds}}+\frac{\mathrm{d}}{\mathrm{dt}} \varphi_{\mathrm{ds}}-\omega \varphi_{\mathrm{qs}} \\
& \mathrm{V}_{\mathrm{qr}}^{\prime}=\mathrm{R}_{\mathrm{r}}^{\prime} \mathrm{r}^{\prime}{ }_{\mathrm{qr}}+\frac{\mathrm{d}}{\mathrm{dt}} \varphi_{\mathrm{qr}}^{\prime}+\left(\omega-\omega_{\mathrm{r}}\right) \varphi_{\mathrm{ds}}^{\prime} \\
& \mathrm{V}_{\mathrm{dr}}^{\prime}=\mathrm{R}_{\mathrm{r}}^{\prime}{ }^{\prime}{ }_{\mathrm{dr}}+\frac{\mathrm{d}}{\mathrm{dt}} \varphi_{\mathrm{dr}}^{\prime}-\left(\omega-\omega_{\mathrm{r}}\right) \varphi_{\mathrm{qs}}^{\prime} \\
& \mathrm{T}_{\mathrm{e}}=1.5 \mathrm{p}\left(\varphi_{\mathrm{ds}} \mathrm{i}_{\mathrm{qs}}-\varphi_{\mathrm{qs}} \mathrm{i}_{\mathrm{ds}}\right)
\end{aligned}
$$

where,

$$
\begin{gathered}
\varphi_{\mathrm{qs}}=\mathrm{L}_{\mathrm{s}} \mathrm{i}_{\mathrm{qs}}+\mathrm{L}_{\mathrm{m}} \mathrm{i}_{\mathrm{qr}} \\
\varphi_{\mathrm{ds}}=\mathrm{L}_{\mathrm{s}} \mathrm{i}_{\mathrm{ds}}+\mathrm{L}_{\mathrm{m}} \mathrm{i}^{\prime}{ }_{\mathrm{dr}} \\
\varphi_{\mathrm{qr}}^{\prime}=\mathrm{L}_{\mathrm{r}}^{\prime} \mathrm{i}_{\mathrm{qr}}{ }^{\prime}+\mathrm{L}_{\mathrm{m}} \mathrm{i}_{\mathrm{qs}}{ }^{\prime} \\
\varphi_{\mathrm{dr}}^{\prime}=\mathrm{L}_{\mathrm{r}}^{\prime} \mathrm{i}^{\prime}{ }_{\mathrm{dr}}+\mathrm{L}_{\mathrm{m}} \mathrm{i}_{\mathrm{q}}{ }_{\mathrm{qs}}
\end{gathered}
$$

Also, the mechanical part was described with the following equations.

$$
\begin{gathered}
\frac{d}{d t} \omega_{m}=\frac{1}{2 H}\left(T_{e}-F \omega_{m}-T_{m}\right) \\
\frac{d}{d t} \theta_{m}=\omega_{m}
\end{gathered}
$$




\subsubsection{Wind turbine modeling}

The extracted aerodynamic torque $\left(\mathrm{T}_{\mathrm{w}}\right)$ is computed as a function of the air density (Q), the swept area $(A)$, the wind speed $(u)$ and the power coefficient factor $\left(C_{p}\right)$ as,

$$
\mathrm{T}_{\mathrm{w}}=\frac{1}{2} \mathrm{QAu}{ }^{2} \frac{\mathrm{C}_{\mathrm{p}}}{\lambda}
$$

Where the tip speed ratio $(\lambda)$ is expressed as a function of the blade length $(R)$ and the blade angular velocity $\left(\omega_{\mathrm{b}}\right)$ as,

$$
\lambda=\frac{\omega_{\mathrm{b}} \mathrm{R}}{\mathrm{u}}
$$

The relations among the developed electrical torque $\left(\mathrm{T}_{\mathrm{g}}\right)$, the mechanical torque $\left(\mathrm{T}_{\mathrm{m}}\right)$ and the extracted aerodynamic torque $\left(\mathrm{T}_{\mathrm{w}}\right)$ can be described as functions of the angular velocities of the wind turbine rotor $\left(\omega_{\mathrm{r}}\right)$ and the generator shaft $\left(\omega_{\mathrm{g}}\right)$ as,

$$
\begin{gathered}
T_{w}-T_{m}=J_{r} \frac{d \omega_{r}}{d t} \\
T_{m}=D_{m c}\left(\omega_{r}-\omega_{g}\right)+K_{m c} d\left(\omega_{r}-\omega_{g}\right) d t \\
T_{m}-T_{g}=J_{g} \frac{d \omega_{g}}{d t}
\end{gathered}
$$

Where the constants $\mathrm{J}_{\mathrm{r}}, \mathrm{J}_{\mathrm{g}}, \mathrm{D}_{\mathrm{mc}}$ and $\mathrm{K}_{\mathrm{mc}}$ are assigned for wind turbine rotor inertia, generator shaft inertia, mechanical coupling damping and mechanical coupling stiffness respectively [36].

\subsubsection{Control system modeling}

The pitch angle is controlled for limiting the generated power for larger wind speed over the predetermined normal one. The pitch control was accomplished simply with a PI controller, whereas the pitch servo is modeled with a first order delay system with a time constant $T_{d}$ as shown in Fig. 6.

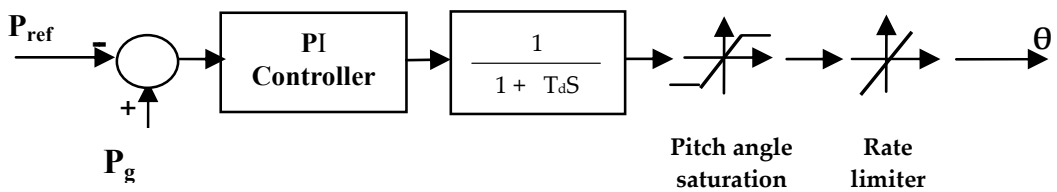

Figure 6. Pitch angle control schematic 


\subsubsection{Calculation of the FSIG active and reactive powers}

Assuming the bus at which the induction generator is connected with the considered power system to be a voltage controlled bus, the load flow computations are carried out to determine the bus injected reactive power $\mathrm{Q}_{\mathrm{inj}}$ and its voltage angle. Loop current equations are written as

$$
\begin{gathered}
V_{s}\left\llcorner\delta=-\left(r_{s}+j X_{s}+j X_{m}\right) I_{s}\left\llcorner\theta_{s}+j X_{m}{ }^{*} I_{r}\left\llcorner\theta_{r}\right.\right.\right. \\
0=j X_{m}{ }^{*} I_{s}\left\llcorner\theta_{s}-\left(\frac{r_{r}}{s}+j X_{r}+j X_{m}\right) I_{r}\left\llcorner\theta_{r}\right.\right.
\end{gathered}
$$

Separating the real and imaginary values in eqns. (17) and (18), it is obtained the following equations,

$$
\begin{gathered}
\mathrm{V}_{\mathrm{s}} \cos \delta=-\mathrm{I}_{\mathrm{s}}\left[\mathrm{r}_{\mathrm{s}} \cos \theta_{\mathrm{s}}-\left(\mathrm{X}_{\mathrm{s}}+\mathrm{X}_{\mathrm{m}}\right) \sin \theta_{\mathrm{s}}\right]-\mathrm{I}_{\mathrm{r} L}\left[\mathrm{X}_{\mathrm{m}} \sin \theta_{\mathrm{r}}\right] \\
\mathrm{V}_{\mathrm{s}} \sin \delta=-\mathrm{I}_{\mathrm{s}}\left[\mathrm{r}_{\mathrm{s}} \sin \theta_{\mathrm{s}}+\left(\mathrm{X}_{\mathrm{s}}+\mathrm{X}_{\mathrm{m}}\right) \cos \theta_{\mathrm{s}}\right]+\mathrm{I}_{\mathrm{r}}\left[\mathrm{X}_{\mathrm{m}} \cos \theta_{\mathrm{r}}\right] \\
0=-\mathrm{I}_{\mathrm{s}}\left[\mathrm{X}_{\mathrm{m}} \sin \theta_{\mathrm{s}}\right]-\mathrm{I}_{\mathrm{r}}\left[\frac{\mathrm{r}_{\mathrm{r}}}{\mathrm{s}} \cos \theta_{\mathrm{r}}-\left(\mathrm{X}_{\mathrm{s}}+\mathrm{X}_{\mathrm{m}}\right) \sin \theta_{\mathrm{s}}\right] \\
0=\mathrm{I}_{\mathrm{s}}\left[\mathrm{X}_{\mathrm{m}} \cos \theta_{\mathrm{s}}\right]-\mathrm{I}_{\mathrm{r}}\left[\frac{\mathrm{r}_{\mathrm{r}}}{\mathrm{s}} \sin \theta_{\mathrm{r}}+\left(\mathrm{X}_{\mathrm{s}}+\mathrm{X}_{\mathrm{m}}\right) \cos \theta_{\mathrm{s}}\right]
\end{gathered}
$$

Then, the generator output active power equation can be written as

$$
P_{\text {out }}=-\frac{I_{r}^{2}}{s} r_{r}-I_{s}^{2} r_{s}
$$

Also, the induction generator input reactive power $\mathrm{Q}_{\mathrm{IG}}$ is computed as

$$
Q_{I G}=I_{s}^{2} X_{s}+I_{r}^{2} X_{r}+\mid I_{s}\left\llcorner\theta_{s}-I_{r}\left\llcorner\left.\theta_{r}\right|^{2} X_{m}\right.\right.
$$

\subsection{DFIG wind generator modeling}

\subsubsection{Mathematical representation of DFIG}

The mechanical, electrical power and the slip (s) of the DFIG could be obtained from the equations

$$
P_{m} \approx-P_{r} \frac{1-s}{s} \approx P_{s}+P_{r}, P_{r}=-s P_{s}
$$


where:-

$$
s=\frac{\omega_{s}-\omega_{r}}{\omega_{s}}
$$

Pm, Ps, Pr are the mechanical, stator, and rotor power respectively. $\omega$ s, $\omega r$ the synchronous and rotor speed respectively.

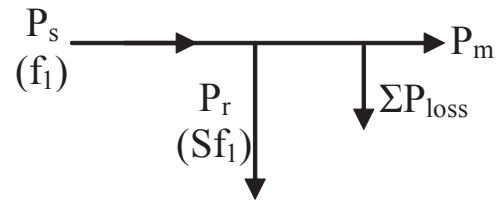

Motoring

$\mathbf{P}_{\mathbf{r}}$ delivered

$\mathbf{P}_{\mathrm{s}}$ absorbed
$\mathrm{S}>0$

$\omega_{\mathrm{r}}<\omega_{\mathrm{s}}$

Sub synchronous
$\mathrm{P}_{\mathrm{s}}$

$\left(f_{1}\right)$

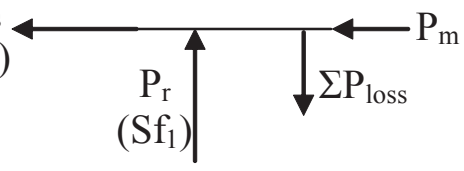

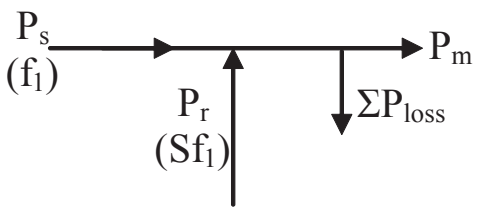

Motoring

$\mathbf{P}_{\mathbf{r}}$ absorbed

$\mathbf{P}_{\mathbf{s}}$ absorbed
$\mathrm{P}_{\mathrm{s}}$

$\left(\mathrm{f}_{1}\right)$

Generating

$\mathbf{P}_{\mathbf{r}}$ absorbed

$\mathbf{P}_{\mathrm{s}}$ delivered

Figure 7. Operation modes of WRIG.

Power exchanging between the DFIG and the grid is complicated depending upon the rotor slip "s" and weather the machine speed is either over or below the synchronous speed. As noticed from Equ.1, the higher the slip, the larger the electric power absorbed (or delivered) through the rotor. DFIG is used in applications with limited speed control range $(|S \operatorname{Smax}|<0.2$ to 0.3 ), so the rating of the rotor-side static converter is around PSN $\mid$ Smax $\mid$, where PSN is the rated stator power. Running into the generating (or motoring) mode is determined by the sign of rotor slip "s" and the active power input (or extracted) electrically from the rotor "Pr". As 
summarized in Fig. 7, the DFIG can operate in the generating or the motoring mode whenever it runs either sub-synchronously $(\omega r<\omega s)$ or super- synchronously $(\omega \mathrm{r}>\omega \mathrm{s})$ [37]. The rotorside converter operates as a rectifier and stator-side converter operate as an inverter for motoring mode (with sub-synchronous speed) or for generating mode (with super-synchronous speed), whereas the slip power delivered from the rotor. The rotor-side converter operates as an inverter and stator-side converter as a rectifier for generating mode (with subsynchronous speed) or for the motoring mode (with super-synchronous speed), whereas the slip power is supplied to the rotor. At the synchronous speed, slip power is taken from supply to excite the rotor windings and in this case machine behaves as a synchronous machine [38]. The power flow through the rotor winding depends mainly on the rotor speed. If the rotor runs super-synchronously, both stator and rotor generated powers are fed to the grid, whereas rotor circuitry is fed with active power in the sub-synchronous mode. On the other hand, the reactive power flow can be calculated as,

$$
\begin{gathered}
Q_{s}+Q_{r}=3 \operatorname{Im} a g\left(V_{s} I_{s}^{*}\right)+3 \operatorname{Im} a g\left(\frac{V_{r} I_{r}^{*}}{S}\right) \\
=3 \omega_{s}\left(L_{s l} I_{s}^{2}+L_{r l} I_{r}^{2}+L_{m} I_{m}^{2}\right)
\end{gathered}
$$

where

Qs, Qr are stator and rotor reactive power.

Vs, Vr, Is, Ir are the voltage and current of the stator and the rotor respectively.

Lsl, Lrl, Lm are the stator leakage, rotor leakage, and magnetizing inductances respectively.

Hence, the reactive power required to machine excitation may be provided by the rotor, the stator or by both. If the stator operates at unity power factor $(\varphi s=0)$, the rotor-side static power converter has to deliver reactive power extracted either internally (through DC linking capacitor) or absorbed from the grid (over-excited DFIG). For under excitation conditions, on the other hand, unity power factor is assumed in the rotor winding $(\varphi r=0)$ extracting the required excitation from the stator winding.

\subsubsection{Principles of vector control of RSC}

Vector control aims principally (for induction machines) to perform the control action in order to produce high-dynamic performance similar to those realized with DC machines. To achieve this target, the reference frames may be aligned with the stator flux-linkage space vector, the rotor flux-linkage space vector or the magnetizing space vector. Stator-Flux Oriented vector control approach is deployed for RSC to provide independent control of active and reactive power. In other words, the vector-controlled DFIG enables the decoupling between active and reactive power as well as between the torque and the power factor [38].

The most common approach in dynamic modeling of DFIGs for wind turbines is using a space vector theory based model of a slip-ring induction machines [37]. 
The space-phasor model of the WRIG, for steady state, in synchronous rotating reference frame, is characterized by DC quantities that make it suitable for control design by transforming into $d-q$ axis using the Park transformation. After transforming from abc to $d-q$ coordinates, the voltage equations of the IM in a general rotating reference frame are calculated from.

$$
\begin{gathered}
V_{d s}=\frac{d \Psi_{d s}}{d t}+R_{s} i_{d s}-\omega_{s} \Psi_{q s}, \quad V_{q s}=\frac{d \Psi_{q s}}{d t}+R_{s} i_{q s}+\omega_{s} \Psi_{d s} \\
V_{d r}=\frac{d \Psi_{d r}}{d t}+R_{r} i_{d r}-\left(\omega_{s}-\omega_{r}\right) \Psi_{q r} \\
V_{q r}=\frac{d \Psi_{q r}}{d t}+R_{r} i_{q r}+\left(\omega_{s}-\omega_{r}\right) \Psi_{d r} .
\end{gathered}
$$

where,

Vds, Vqs, Ids, Iqs are the stator voltages, and currents in d-q reference frame, respectively.

Vdr, Vqr, Idr, Iqr are the rotor voltages, and currents in d-q reference frame, respectively.

$\psi \mathrm{ds}, \psi \mathrm{qs}, \psi \mathrm{rs}, \psi \mathrm{qr}$ are the flux linkages in d-q reference frame for stator and rotor respectively.Rs, $\mathrm{Rr}$ are the stator and rotor resistances, respectively.

Flux linkage equations for stator and rotor windings can be calculated as,

$$
\begin{aligned}
& \Psi_{d s}=L_{s} I_{d s}+L_{m} I_{d r}, \quad \Psi_{q s}=L_{s} I_{q s}+L_{m} I_{q r} \\
& \text { where } L_{s}=L_{s l}+L_{m} \\
& \Psi_{d r}=L_{r} I_{d r}+L_{m} I_{d s}, \quad \Psi_{q r}=L_{r} I_{q r}+L_{m} I_{q s} \\
& \text { where } L_{r}=L_{r l}+L_{m}
\end{aligned}
$$

For the rotor-side controller the d-axis of the rotating reference frame used for d-q transformation is aligned with air-gap flux $\psi_{\mathrm{s}}$. Aligning the system of coordinates to stator flux seems most useful, as, at least for power grid operation, $\psi_{\mathrm{s}}$ is almost constant, because the stator voltages are constant in amplitude, frequency, and phase [37]. Aligning the d-axis of rotating reference frame to the stator flux linkage (stator flux oriented control) will result in,

$$
\overline{\Psi_{s}}=\Psi_{s}=\Psi_{d s} \quad, \quad \Psi_{q s}=0, \quad \frac{d \Psi_{q s}}{d t}=0
$$

Since the variation of the stator flux $\psi$ ds is considered to be very small, $\frac{d \Psi_{d s}}{d t}=0$. 
Then, Eqns. (30) and (31) can be rewritten as,

$$
I_{q s}=-\frac{L_{m}}{L_{s}} I_{q r}, \quad I_{d s}=\frac{\Psi_{d s}-L_{m} I_{d r}}{L_{s}}
$$

Then, neglecting the stator resistance (Rs) simplified Eqns. (3) and (4) to be expressed as:,

$$
V_{d s}=0, \quad V_{q s}=\omega_{s} \Psi_{d s}
$$

The resulting active and reactive power can be calculated as,

$$
\begin{aligned}
& P_{s}=\frac{3}{2}\left(V_{d s} I_{d s}+V_{q s} I_{q s}\right)=\frac{3}{2} V_{q s} I_{q s}=-\frac{3}{2} \frac{L_{m}}{L_{s}} \omega_{s} \Psi_{d s} I_{q r} \\
& Q_{s}=\frac{3}{2}\left(V_{q s} I_{d s}-V_{d s} I_{q s}\right)=\frac{3}{2} V_{q s} I_{d s}=\frac{3}{2 L_{s}} \omega_{s} \Psi_{d s}\left(\Psi_{d s}-L_{m} I_{d r}\right)
\end{aligned}
$$

Eqn. (35) clearly shows that the active power delivered (or absorbed) under stator flux orientation control by the stator, Ps, may be controlled through the rotor current Iqr, while the reactive power (at least for constant $\psi \mathrm{s}$ ) may be controlled through the rotor current Idr. As pulse-width modification on the machine-side converter is generally performed on rotor voltages, voltage decoupling in the rotor is required. Substituting from Eqn. (33) into Eqn. (31) yields,

$$
\Psi_{d r}=L_{s c} I_{d r}+\frac{L_{m}}{L_{s}} \Psi_{d s}, \Psi_{q r}=L_{s c} I_{q r}, \quad L_{s c}=L_{r}-\frac{L_{m}^{2}}{L_{s}}
$$

Substituting from Eqn. (11) into Eqn. (4) yields,

$$
\begin{aligned}
& V_{d r}=R_{r} i_{d r}+L_{s c} \frac{d I_{d r}}{d t}-\left[s \omega_{s} L_{s c} I_{q r}\right] \\
& V_{q r}=R_{r} i_{q r}+L_{s c} \frac{d I_{q r}}{d t}+\left[s \omega_{s}\left(\frac{L_{m}}{L_{s}} \Psi_{d s}+L_{s c} I_{d r}\right)\right], \\
& s \omega_{s}=\omega_{s}-\omega_{r}
\end{aligned}
$$

Eqn. (37) constitutes the rotor voltage decoupling conditions, where the terms in brackets represent the decoupling or compensating terms. Adding these compensating terms to the 
corresponding uncompensated voltage terms (the outputs of the current controllers which control Isd and Isq components) makes it possible to achieve decoupled performance of the stator flux-oriented control of the rotor-side converter [38], [39]. The overall control scheme, described before, was summarized in Fig. 8.

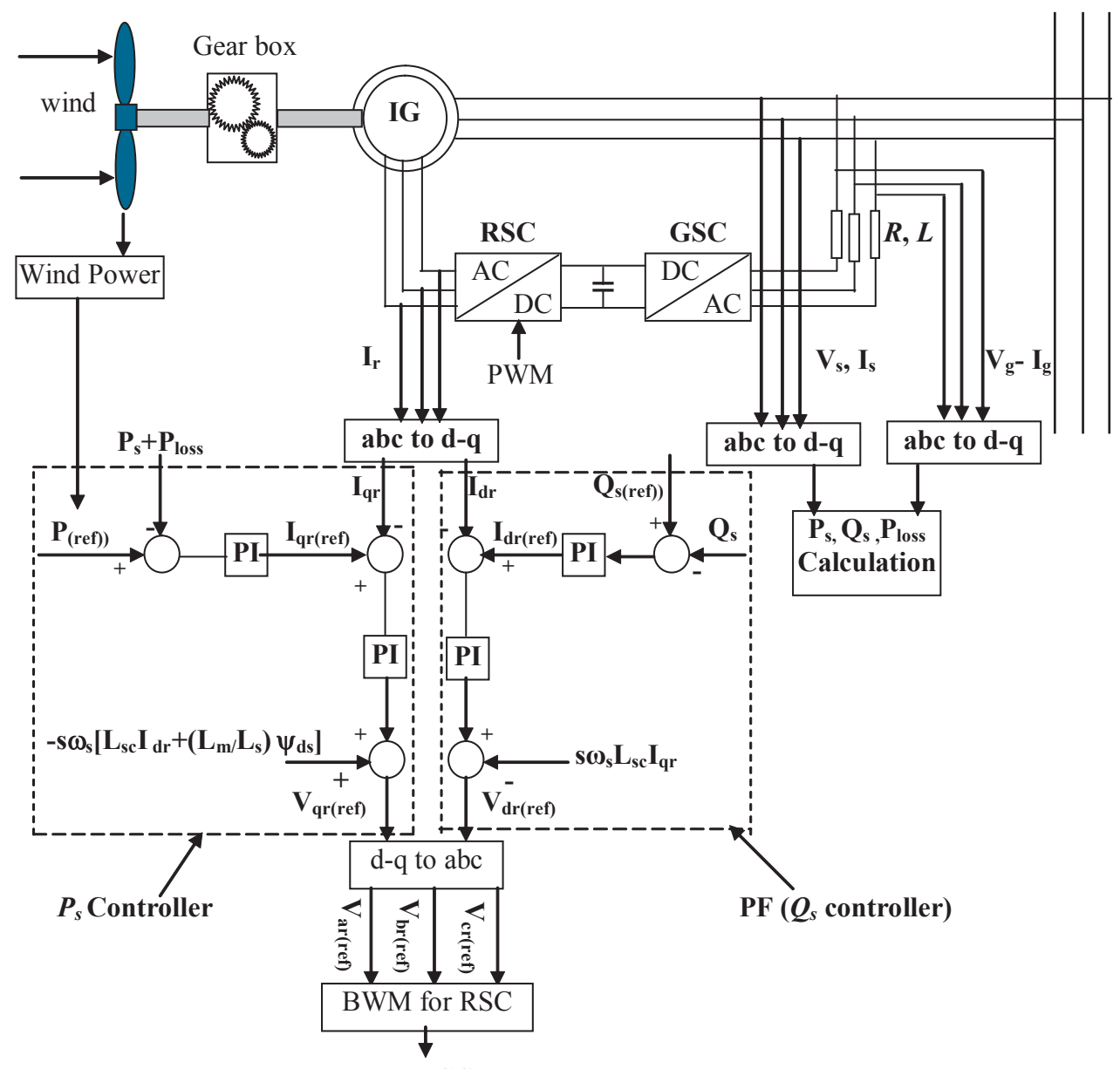

To RSC

Figure 8. Vector control structural diagram of the RSC for DFIGs.

The reference power, $\mathrm{P}_{\mathrm{s}}(\mathrm{ref})$, is calculated from the power speed curve of the wind turbine. The ABCD locus represents the maximum power control action as illustrated in Fig. 9. Each of these curves was structured for a certain wind speed as a function of the air density (@), the 
turbine blade radius $(\mathrm{R})$, the tip speed ratio $(\lambda)$, the wind speed $(\mathrm{v})$, the power coefficient $(\mathrm{Cp})$, the pitch angle $(\beta)$ and the wind turbine speed $(\omega t)$ as,

$$
P_{w}=\frac{1}{2} \rho \pi R^{2} v^{3} C_{p}(\lambda, \beta) . \quad \text { where } \quad \lambda=\frac{\omega_{t} R}{v}
$$

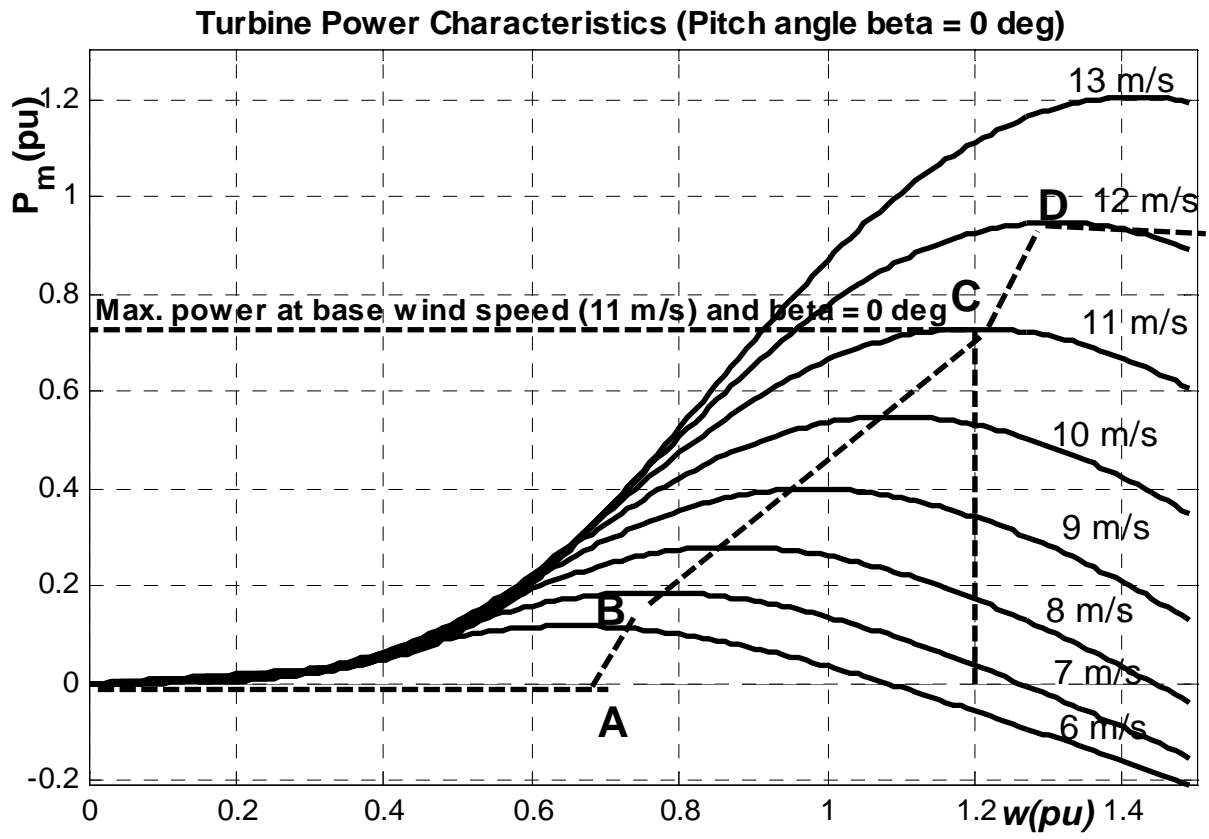

Figure 9. $\mathrm{P}-\omega$ curve and tracking maximum power curve of the wind turbine.

\subsubsection{Principles of vector control of GSC}

The main objective of GSC is to maintain the DC-link voltage to be constant regardless of the magnitude and direction of the slip power Pr. As illustrated in Fig. 10, a current-regulated PWM scheme is used, where $\mathrm{d}$ and $\mathrm{q}$ axes currents are used to regulate DC-link voltage and reactive power. On the other hand, the GSC uses a power filter to reduce current harmonics flow into the power source. The inductance and resistance $(R, L)$ of the input filter are taking into account, so, the voltage equations across the inductor $(\mathrm{L}, \mathrm{R})$ can be written as follows:

$$
V_{g}=R I+L \frac{d I}{d t}+V
$$


Where I, $\mathrm{V}$ are the current and voltage at the grid side. These equations may be translated into $\mathrm{d}-\mathrm{q}$ synchronous coordinates that may be aligned with the positive sequence of grid side voltage $\left(\mathrm{V}_{\mathrm{gq}}=0, \mathrm{~V}_{\mathrm{gd}}=\mathrm{V}_{\mathrm{g}}\right)$ :

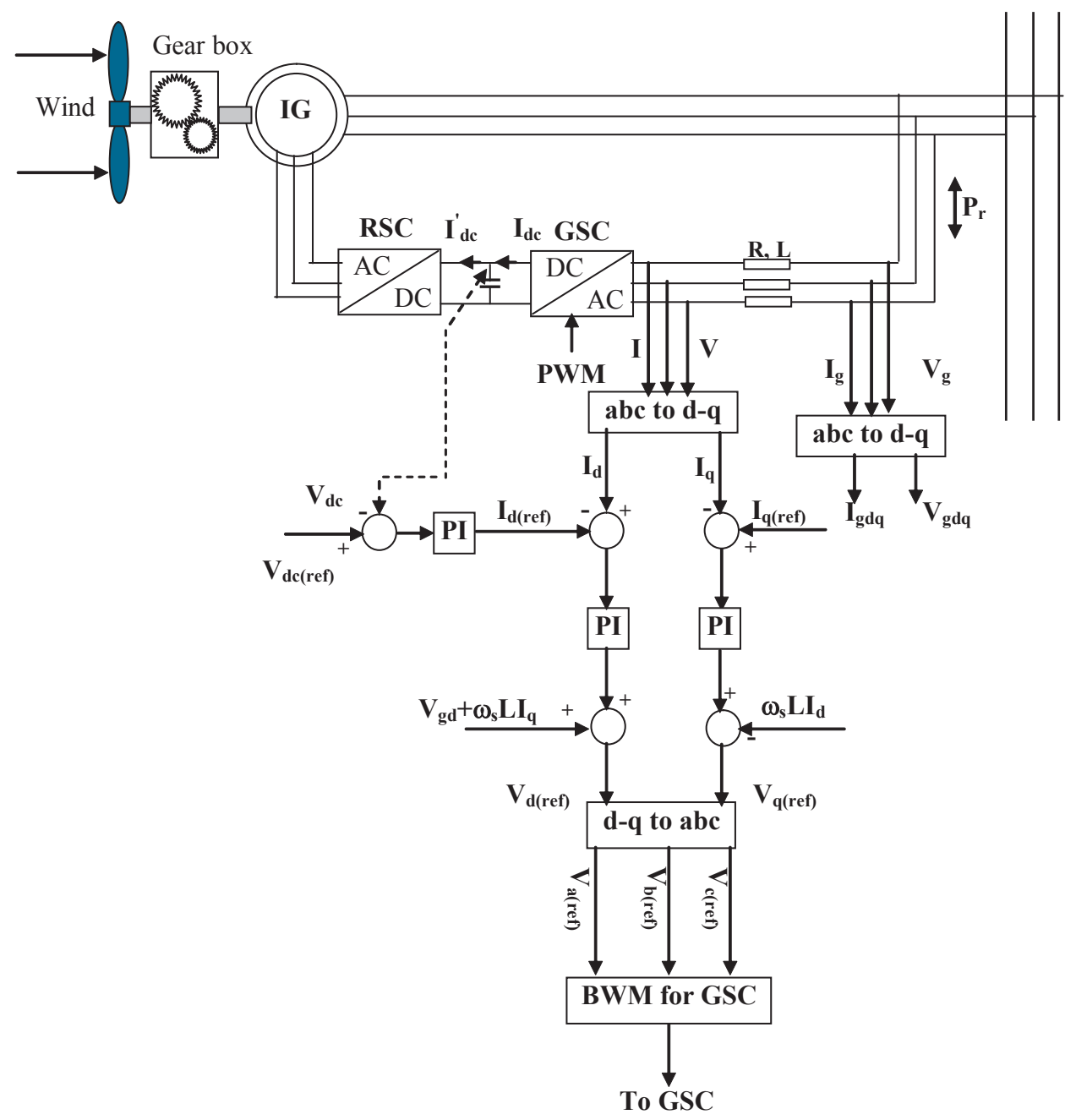

Figure 10. Vector control structural diagram for a GSC of a DFIG. 


\subsubsection{Grid integration issues of DFIGs}

As described in the preceding analysis, the concept of DFIG for variable-speed wind turbine provides the possibility of controlling the active and reactive power, which is significant for grid integration. On the other hand, vector control of the DFIG enables the decoupling between active and reactive power as well as between the torque and the power factor. Hence, unique features of grid supporting are expected [40]-[43]. Owing to the new policies of recent grid codes, wind farms are required to remain grid-connected during grid faults for a certain time so that they can directly contribute with active and reactive power to the grid. This leads to support the overall system stability [44], [45]. On the other hand, wind turbines are separated from the grid following grid faults leading to loss of an undesirable portion of power generation. Hence, most utilities require Fault Ride-Through (FRT) capability for grid-connected wind farms. Theoretically, decoupling between the wind generators and the grid with the utilized back-to-back converters in variable speed machines greatly eliminates impacting the system frequency. However, large penetration of wind energy into the grid leads the spinning reserve to have less time to react to the power imbalance resulting from load variations or wind speed fluctuations. Hence considerable frequency deviations can be expected in the system. Then, grid voltage support by wind generators is essential for eliminating these impacts. Basic control strategies for support the grid was conventionally achieved by controlling the behavior of either the Rotor Side Coveter (RSC) or the Grid Side Converter (GSC) or both of them to maintain the generated active and reactive power of the DFIG during the fault period. Recently, more control loops were proposed utilizing the system frequency response inertial response to do the same action, where the fluctuation in system frequency or apparent system inertia can be utilized to control the profile of the generated power by the wind generators [46]. Also, damping control loops were also proposed to eliminated the expected mechanical oscillations on the DFIG rotor to serve for controlling the generated active and reactive power [41], [47].

Old grid integration scenarios recommend to separate wind generators from the grid when their terminal voltage level decreased below $80 \%$ of its nominal range. Since these scenarios are not acceptable with the increasing penetration wind power plants, recent grid codes demanded that grid integrated wind farms must withstand voltage dips to a certain percentage of its nominal voltage (down to $0 \%$ in some cases) for a specified duration. Differences among these codes were demonstrated in Fig. 11 [48]-[50]. This is mainly to benefit with its capabilities for supporting the grid with reactive power to avoid the possibilities of voltage instability problems as possible. Accordingly, wind turbines are usually considered as active components facilitating grid support when required.

According to Fig. 12 (German grid code), wind turbines have to be still connected to the grid during the elapsed time by areas I and II even when the voltage at the Point of Common Coupling (PCC) with the grid drops to zero. For severe thermal impacts, on the other hand, wind turbines can be separated from the grid and then resynchronized shortly after a few hundreds of milliseconds [48]. During the fault period, power generation by the variable speed wind generator is reduced by the converter control temporarily. Then, grid supporting is released to increase the generated active power to the grid. Once the fault is cleared, the wind turbine controller should be able to increase the active power fed to the grid after 
resynchronization process as fast as possible. In area III short disconnection from the grid is allowed if the voltage cannot return to area II. Within the next two seconds, resynchronization is always required. If the voltage remains low longer than 2.683 seconds, tripping of the corresponding wind turbines by system protection is issued [50], [51].

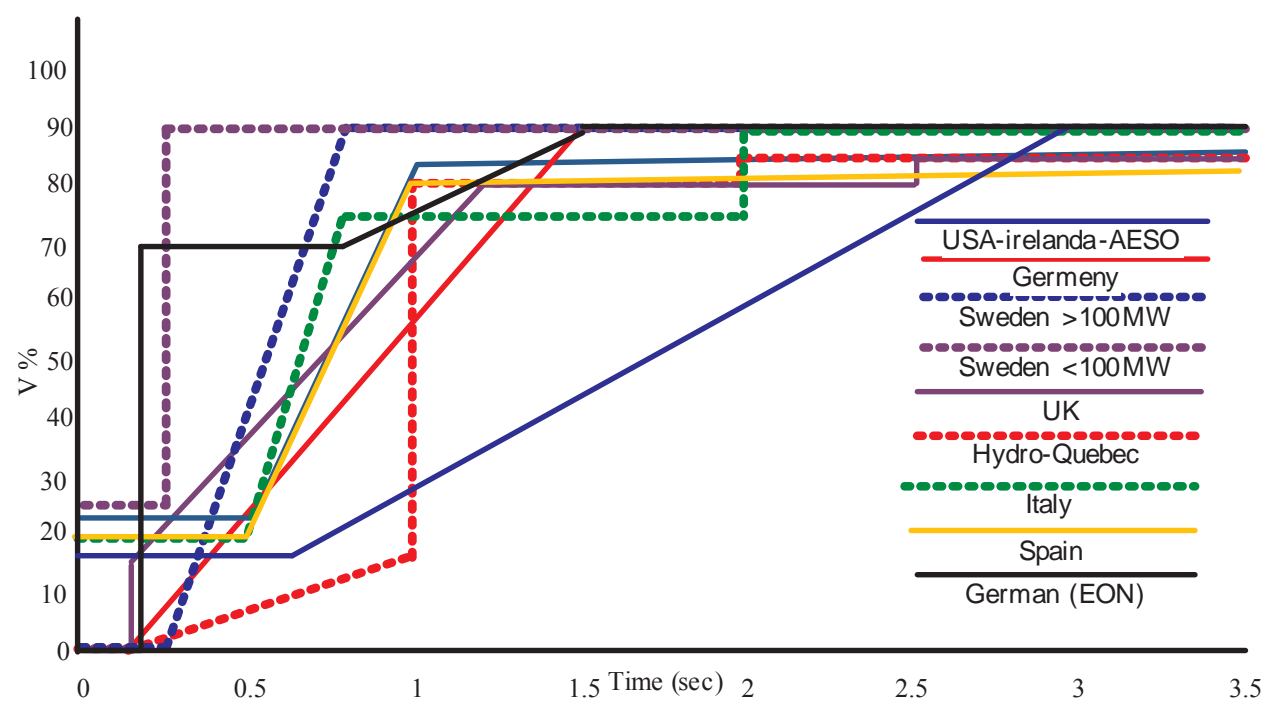

Figure 11. FRT requirements for various grid codes

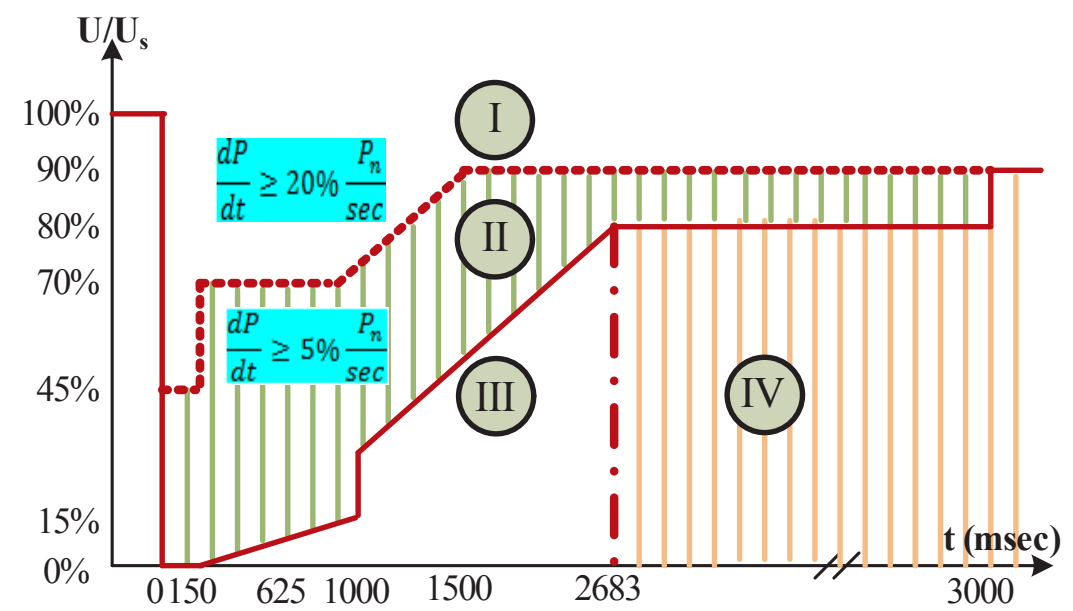

Figure 12. Fault Ride Through capability of wind farm power station 
These grid codes assisted different possible voltage control strategies for regulating the terminal voltage DFIG wind turbines during normal/abnormal operation. Principally, DF I IG voltage can be controlled by either the RSC [45] or the GSC [52] or by both of them to support the grid by generating reactive power during network faults and restore the grid voltage as possible. If the PCC voltage is dropped more than $10 \%$ of the RMS of the generator terminal voltage, the wind generator must be switched to voltage support mod. As described in Fig. 3, the network voltage support is initiated within $20 \mathrm{~ms}$. by providing reactive power at the generator terminals. A reactive power output of $100 \%$ of the rated current must be possible if necessary as well. On the other hand, it is worthy to note that the requirements described in Fig 13 are not applicable when the wind turbine generator output power is less than $5 \%$ of its rated power or during very high wind speed conditions [50].

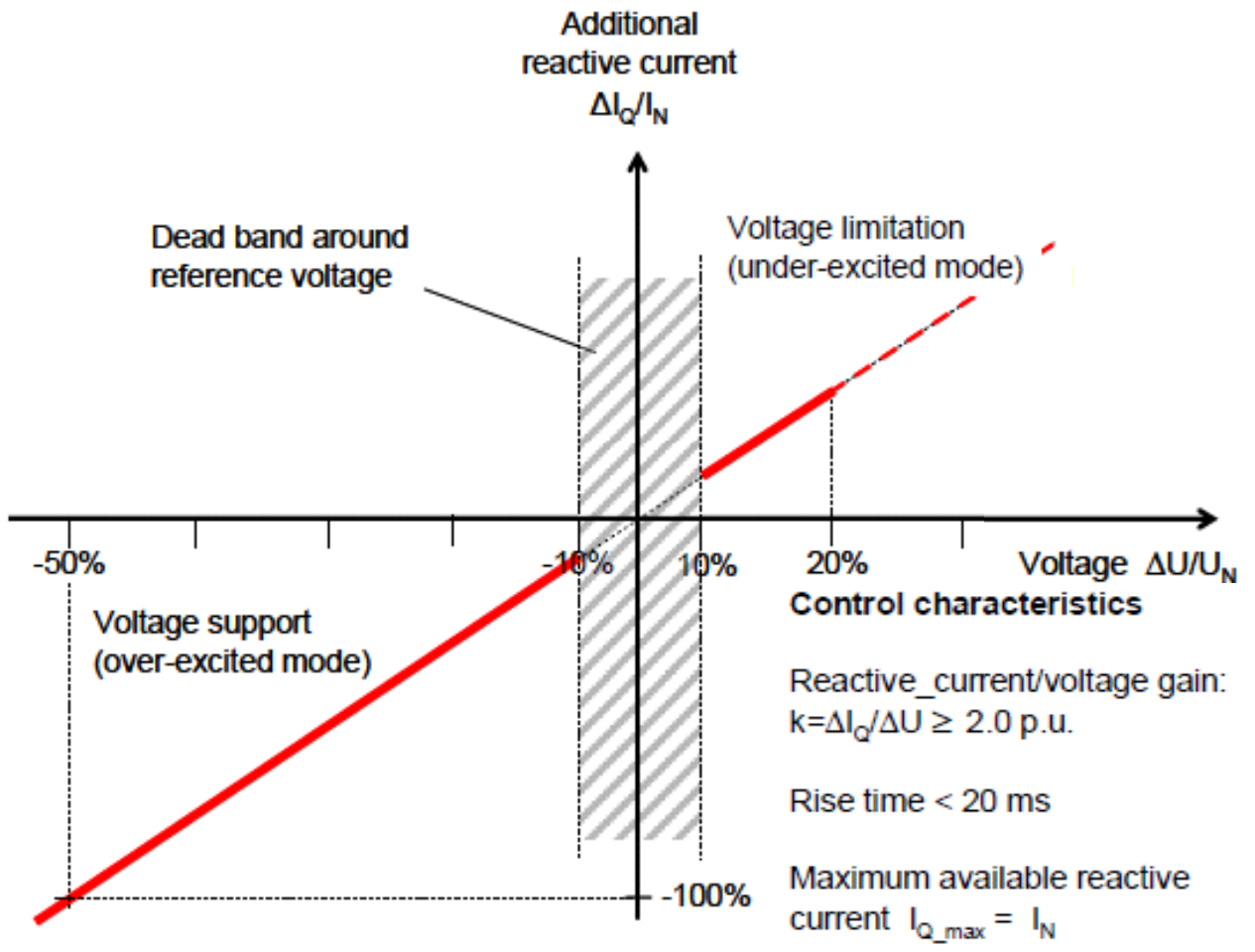

Figure 13. Recommended voltage German support profile

\subsubsection{Rotor protection scenarios}

As the consequence of a sudden short circuit on the grid, the stator current of the DFIG may contain DC-components which appear in the rotor side as an AC current. Therefore the rotor current can exceed to more than 2-3 times its nominal value [52]-[56]. This obviously is not 
acceptable, and it can in turn cause large increases in the DC-link voltage or cause damage to the rotor-side converter itself. With the continuous increase in the rotor current or the DCvoltage, the rotor side converter should be disconnected otherwise it will be destructed. So, to satisfy the FRT, keeping the machine connected to the grid without destroying the machine, both of the crowbar and chopper are used in this thesis for the wind farm rotor protection.

The crowbar is a device mounted in parallel with the rotor converter, as sketched in Fig. 14, which comprises a three phase diode bridge that rectifies the rotor currents and a single thyristor in series with a resistor $\mathrm{R}_{\text {crow }}$. For the grid short circuit disturbance the crowbar shortcircuits the rotor terminal, and hence the RSC is separated from the rotor circuit, and the DFIG goes to operate as a FSIG, in which the DFIG is not controlled by the rotor-side converter. The thyristor of the crowbar circuit is triggered by the DC-voltage, at 1.1 of the nominal DC voltage value, which rises due to rotor current increase. After a short time delay of about $60-120 \mathrm{~ms}$ during the crowbar is switched off and the DFIG regain its normal operation.

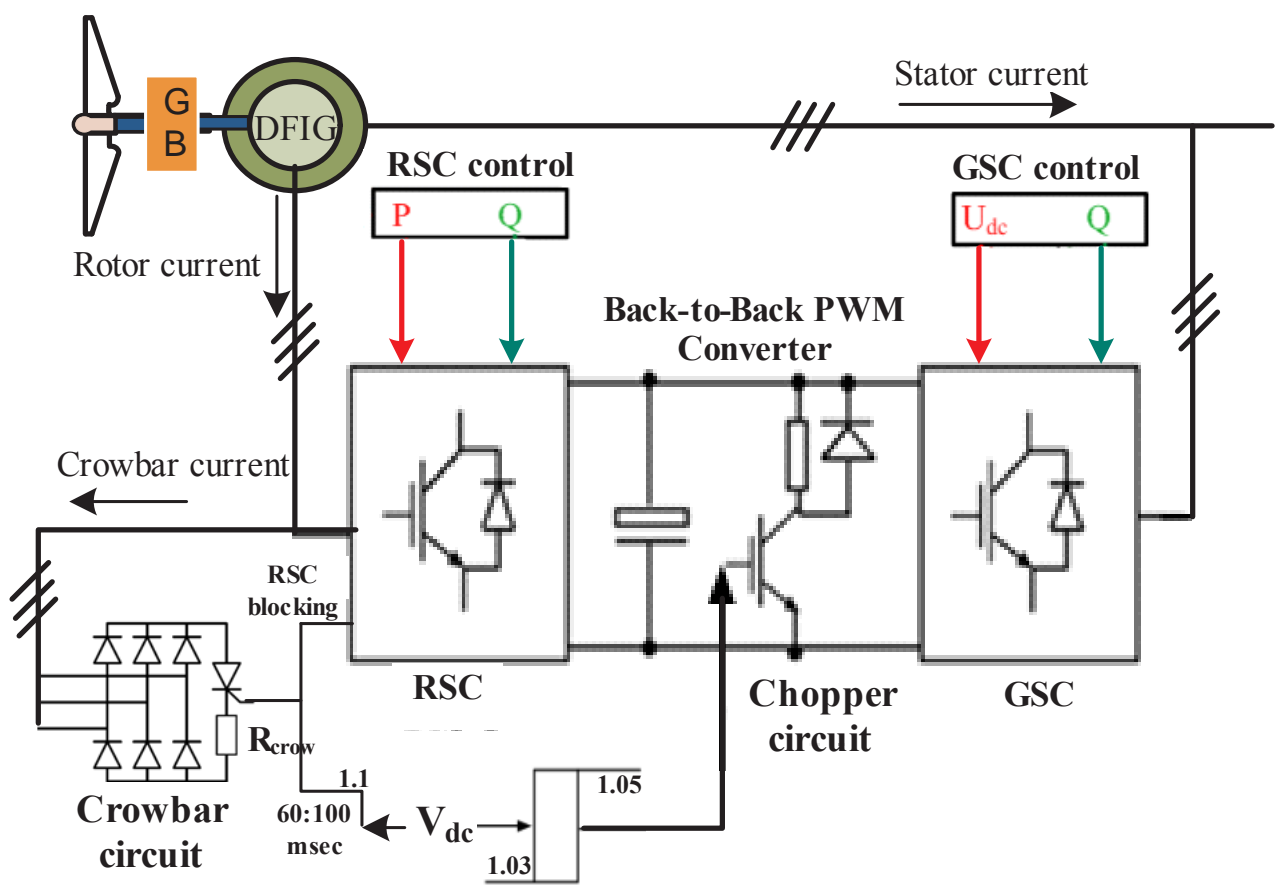

Figure 14. A DFIG equipped with the crowbar and chopper.

According to the situation of operation during the fault, different operation modes occurs affecting the behavior of the DFIG as shown in Fig. 15 as follows [57]-[64]. In Normal mode (mode 1), rotor current and rotor voltage are controlled by the IGBT's. In Crowbar mode (mode 2), the Rotor side IGBT-converter is switched off, whereas the crowbar is switched on. When 
the crowbar is on, the rotor side converter controller is stopped and reset in this mode. Then the machine behaves as a SFIG one. In the No load mode (mode 3), the rotor side IGBT-converter is switched off and consequently the rotor-current $=0$. In Deactivation mode (mode 4), the generator rotor windings are fed by anti-parallel diodes of rotor side converter when the IGBTconverter is deactivated. In mode 4 , the DFIG can be described by the same equations as used for normal mode. However, the absolute value of rotor voltage is determined by the DC-link voltage only.

All these operation scenarios affect the performance of the DFIG generator during grid faults and consequently influence the stability profile of such generators during stability problems.
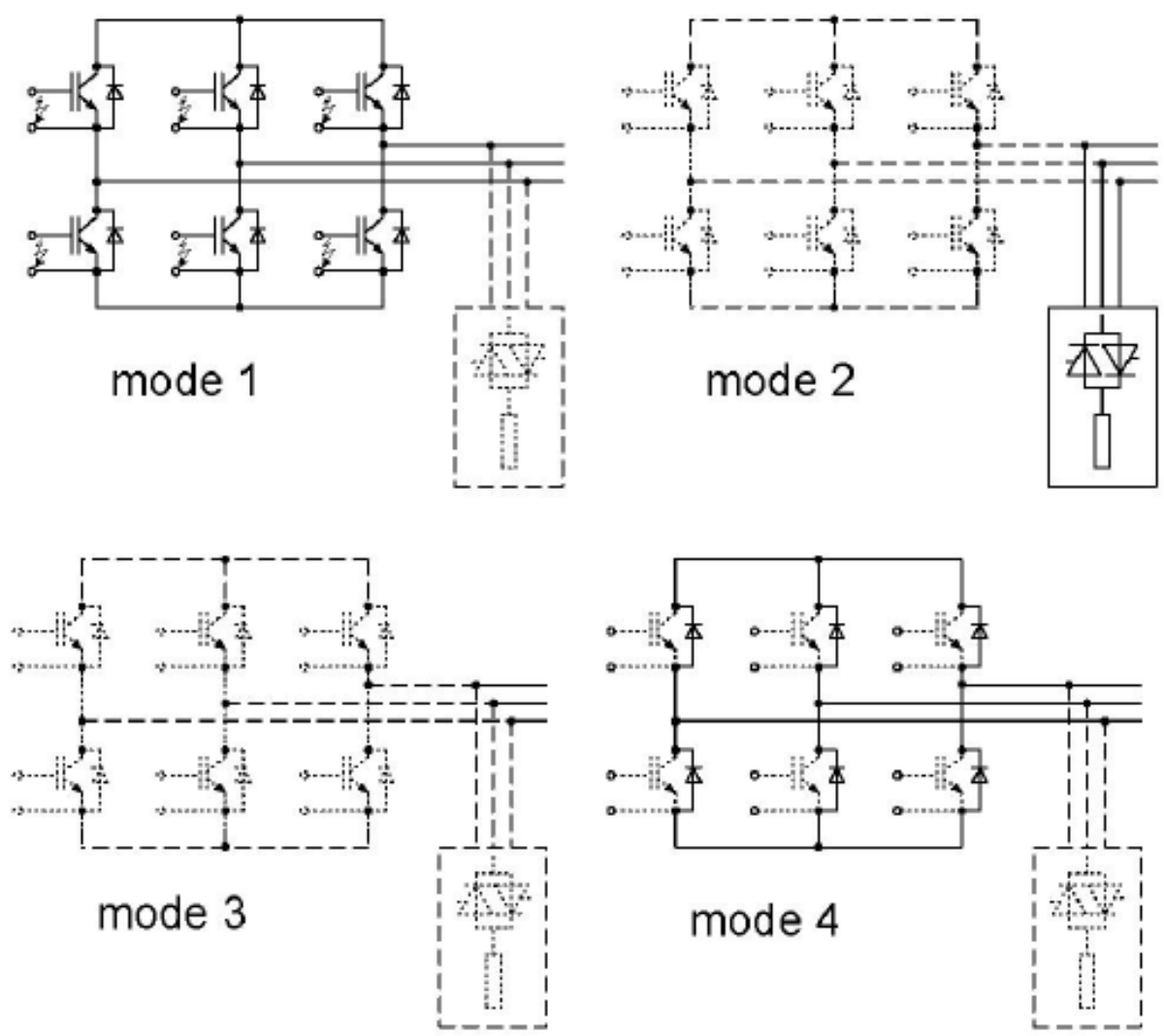

Figure 15. Operation modes with the crowbar operation modes

It is found that, the crowbar ignition converts the DFIG to SFIG by short-circuiting the rotor circuit, and blocking the RSC. During this time the generator acts as a common single fed 
induction generator and consumes reactive power, which is not desirable. Therefore, utilizing crowbar mechanisms has recently replaced with a DC chopper. The DC chopper is used to limit the DC voltage by short-circuiting the DC circuit through the chopper resistors as demonstrated in Fig. 14.

To keep the DC voltage below the upper threshold, 1.05 of the nominal value, the chopper is switched on by IGBT switches and stay in conduction mode until the DC voltage decreased to the lower threshold value, 1.03 of the nominal value. [65].

When the DC voltage is maintained by the chopper the DFIG can be controlled even if it is operating on a low voltage level. However, in extreme situations the DC voltage may increase further and the crowbar must be used to protect the DFIG from damage.

\section{Simulation examples for transient stability studies}

\subsection{Selected testing network}

The well known IEEE standard 3-generator, 9-bus power system, shown in Fig. 16, is considered for preparing the required simulation examples [66]. It is assumed that each of the system generators is equipped with the automatic voltage regulator (AVR) and speed governor as described in Fig. 17 and 18 [67] considering $\mathrm{KA}=25, \mathrm{TA}=0.05, \mathrm{Kg}=50$ and $\mathrm{Tg}=5$.

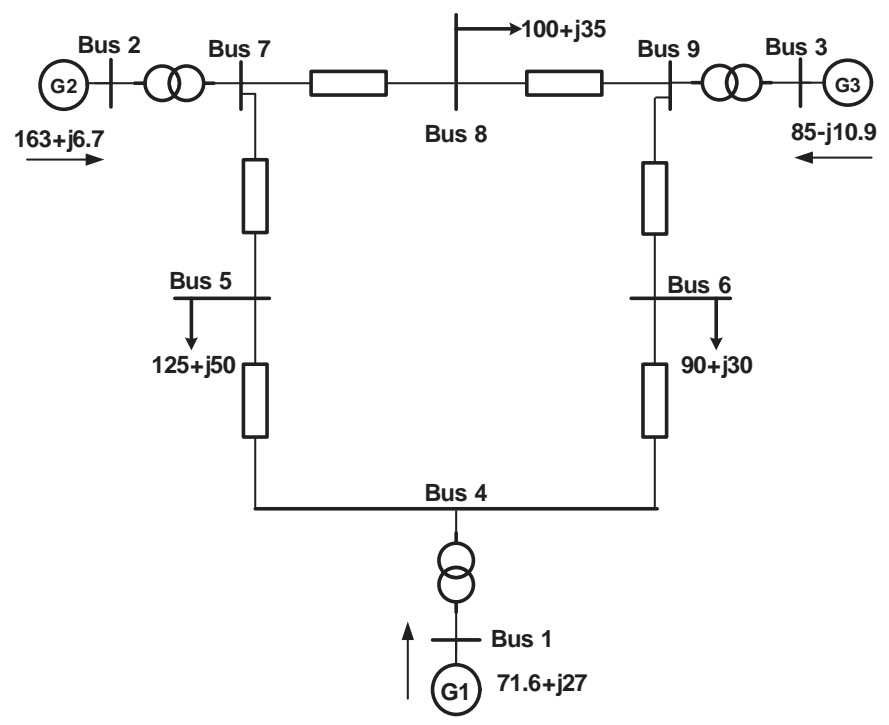

Figure 16. One line diagram of the selected IEEE 9-bus system. 


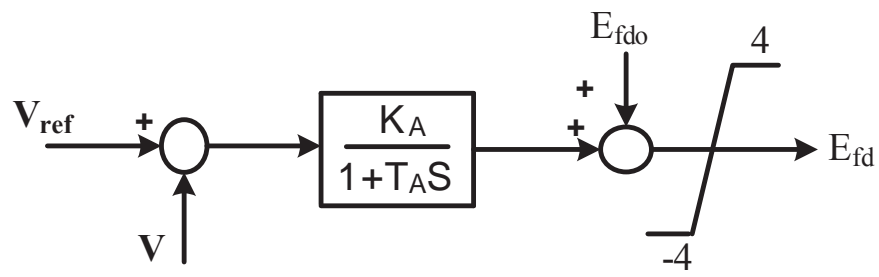

Figure 17. IEEE Type-AC1A Excitation system representation

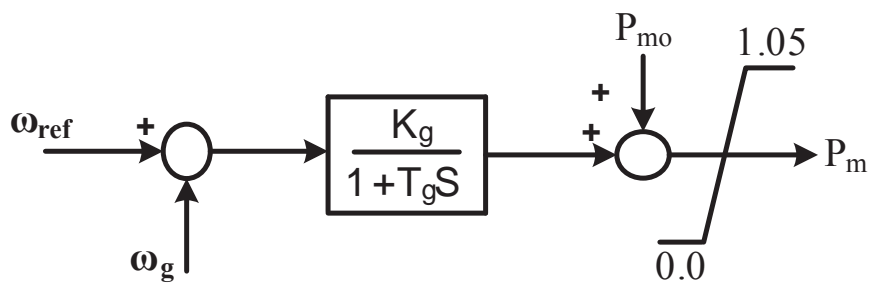

Figure 18. Speed governor system representation

\subsection{Simulated examples for SFIGs}

In order to emphasize the paper aim, a preliminary stability study was performed with the selected IEEE 9-bus system utilizing the developed simulation platform. Effects of considerable amounts of wind energy conversional systems in conjunction with conventional synchronous generators are highlighted. One of these conventional ones (connected at bus 3 ) is replaced by a FSIG equivalent generator representing the overall wind farm. Also, the FSIG output active power is assumed to equal $0.85 \mathrm{pu}$. (the removed generator output power). This power is equal to about $27 \%$ of the system total generated power. Referring to Fig. 4 the FSIG loop current equations are solved. It is found that the generator steady state slip $\mathrm{So}=-0.0181$, and its input reactive power equals $0.4512 \mathrm{pu}$. Hence, after carrying out the system load flow study, it is chosen a capacitor of the reactive power $0.38624 \mathrm{pu}$. to be connected with the FSIG. Each of the system two synchronous generators was represented by the well known three-axis model, whereas the SFIG was represented using the described equations earlier.

A three phase short circuit fault was initiated at $0.10 \mathrm{sec}$. at bus 8 . It is found that both the system synchronous (angle) and voltage stability are lost, as shown in Figs. 19 and 20. The system can maintain its stability when the fault is removed after elapsing a time interval not larger than $0.225 \mathrm{sec}$. from the fault instant. As concluded from the results, the system can maintained its both voltage and synchronous stability, if the faulted line is isolated before 0.285 sec. from the fault instant. On the other hand, the original system (equipped with three 
synchronous generators only) has the critical times for isolating the faults of the first and second locations of 0.25 and $0.3 \mathrm{sec}$. respectively.

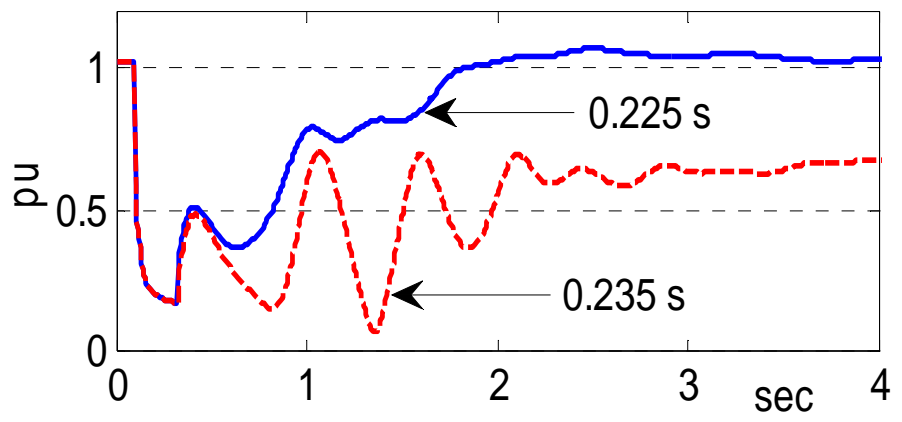

Figure 19. Wind farm terminal voltage for SFIG unit

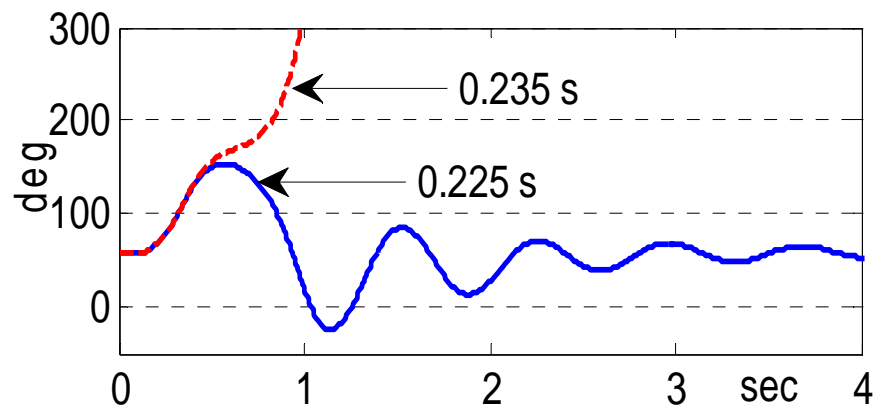

Figure 20. Synchronous machines relative angle $\delta_{21}$ for SFIG unit

Another testing example was carried out when the wind speed was increased from 12 to 15 $\mathrm{m} / \mathrm{sec}$. whereas a 3-phase short circuit fault was applied at bus 8 after $0.1 \mathrm{sec}$. Referring to Figs 21,22 and 23, both the system voltage and frequency stability were maintained when the fault duration time is less than $0.15 \mathrm{sec}$. These presented simulation examples may raise different conclusions. The critical time value for removing a short circuit at one of the system buses or isolating a faulted line, are about $90 \%$ of those for the original power system. This essentially means that replacing a synchronous generator by an FSIG may deteriorate the system stability. For an increase in the wind speed which is followed by a 3-phase short circuit at one of the system buses, the critical time for removing the fault is equal to about $65 \%$ of that for the short circuit fault under the normal wind speed. This means that increasing the wind speed deteriorates the system stability. 


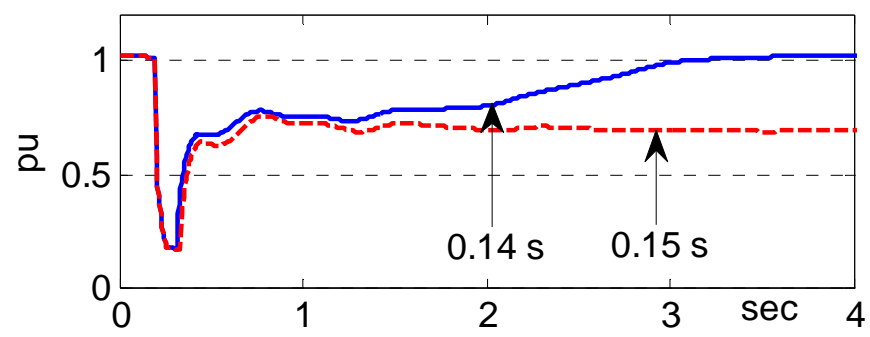

Figure 21. Wind farm terminal voltage for SFIG unit

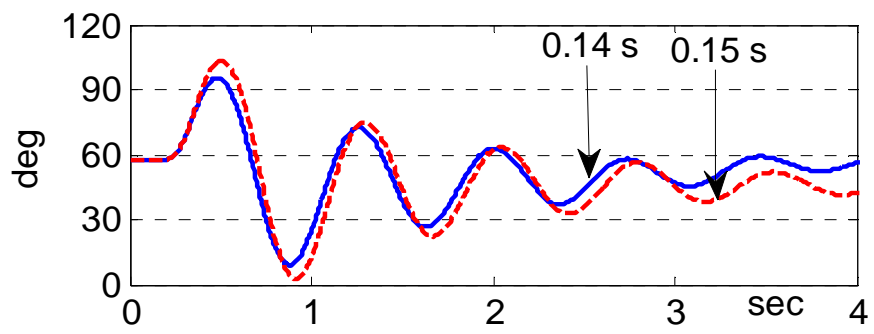

Figure 22. Synchronous machines relative angle $\delta 21$ for SFIG unit

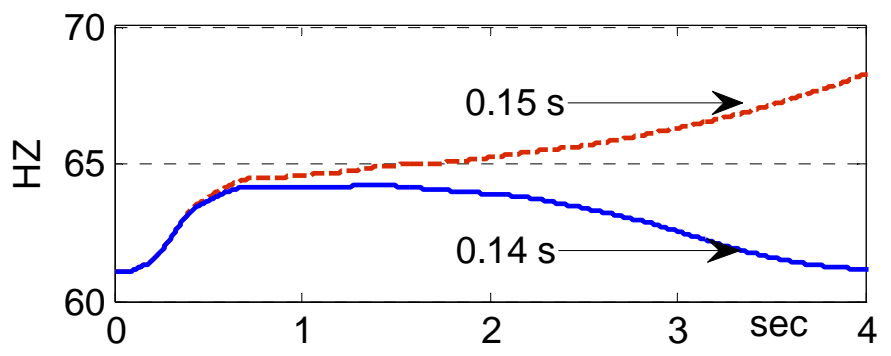

Figure 23. Frequency of the induction generator for SFIG unit

\subsection{Simulated examples for DFIGs}

It was considered that the SFIG was replaced with a DFIG one. Similar tests were applied as described earlier. Unlike the SFIG one, the FRT as well as the rotor protection schemes affected the performance of the DFIG during faults. The crowbar firing is triggered by the DC-voltage (with a threshold of $110 \%$ of its nominal DC voltage) which rises due to the first rotor current 
peak. The IGBT's are usually stopped by its own protection but the current and thus the energy continues to flow into the DC-link through the freewheeling diodes leading to a very fast voltage increase. Crowbar is typically kept on for $60-120 \mathrm{~ms}$ and then it is switched off. Then the converter resynchronizes and the system goes back into controlled DFIG operation. When the crowbar is switched on, the converter is separated from the rotor circuits.

Referring to the developed modeling, Fig. 24 shows the performance of the DFIG during a three phase short circuit while the crowbar circuitry was activated. As a result, rotor, crowbar and stator currents were demonstrated in Fig. 24 (a), (b) and (c) respectively. As soon as the Crowbar DC link voltage exceeded its limit, the crowbar was initiated as shown in Fig. 25(a) and the rotor side converter is blocked. The Crowbar thyrestor firing is switched off after elapsing $100 \mathrm{~ms}$, the DFIG terminal voltage is nearly equal to zero as demonstrated in Fig. 25(b) during the fault period. As noted from Fig. 25(c), there is no output active and reactive power flow during the fault time as well.

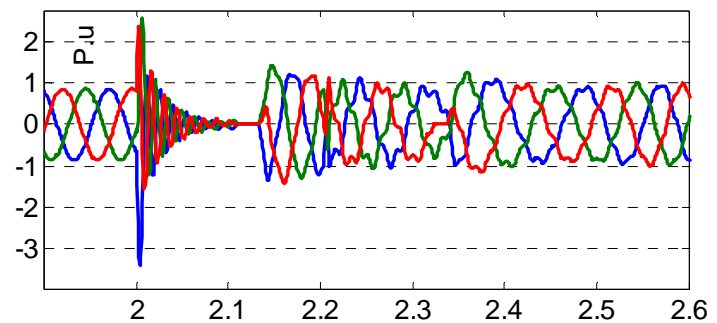

(a)

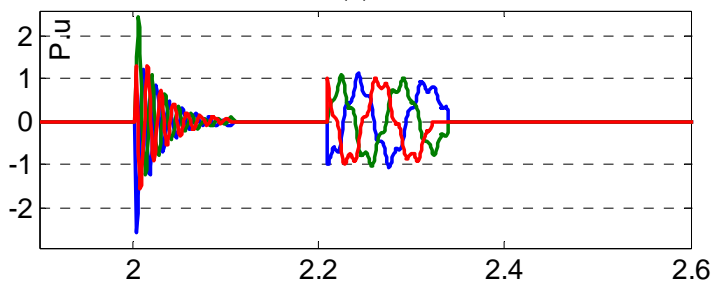

(b)

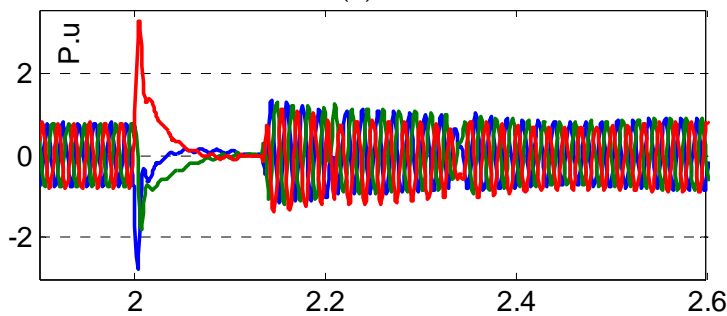

(c)

Figure 24. Behavior of the DFIG for a grid fault at bus B6 with crowbar operation (a) Rotor current (b) Crowbar current (c) Stator current 


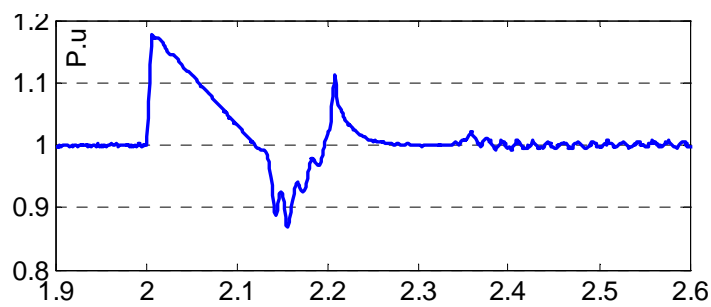

(a)

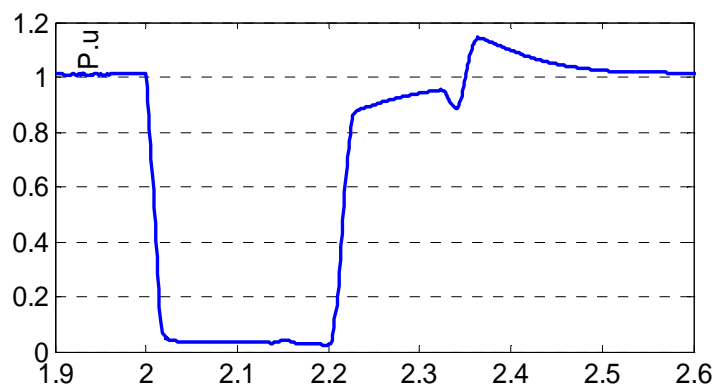

(b)

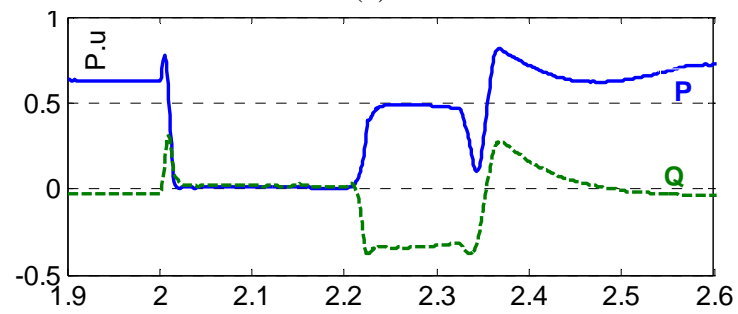

(c)

Figure 25. Response of the DFIG for a grid fault at bus B6 with crowbar operation (a) DC link voltage (b) Terminal voltage of DFIG (c) active/reactive power of DFIG

The fault was repeated considering the chopper operation instead of the crowbar. As described in Fig. 26, the chopper circuit was initiated as soon as the DC voltage exceeded $1.05 \%$ of its nominal value and continue until the DC voltage reduced to 1.03 . Hence, a discontinuous chopper current was observed as shown in Fig. 26(c). Then, the chopper operation protected the rotor winding while keeping variable speed operation of the DFIG during the fault. Unlike the crowbar operation, this facilitates the grid support capabilities during such faults. As a result, a better terminal voltage of the DFIG was realized as compared with the corresponding crowbar response as described in Fig. 27(d).

As emphasized from the results, the use of the chopper improves the profile of the reactive power injection during and after the fault period. After the fault removing the chopper prevent the operation of the crowbar, as compared with its corresponding operation. Then, the DFIG doesn't absorb a reactive power from the grid. Therefore the chopper protection circuit can 
support the PCC voltage remarkably. Different tests were applied revealing the perfect capabilities of the DFIGs for supporting the grid during faults as fully described in [62], [65].

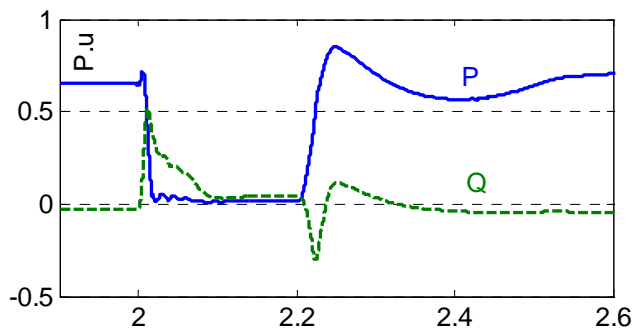

(a)

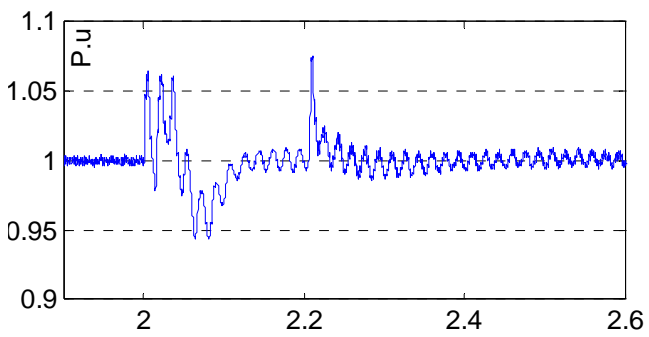

(b)

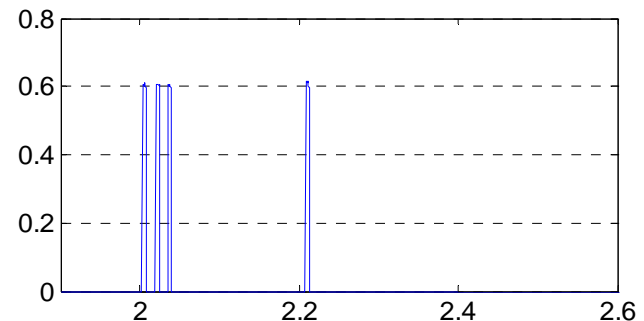

(c)

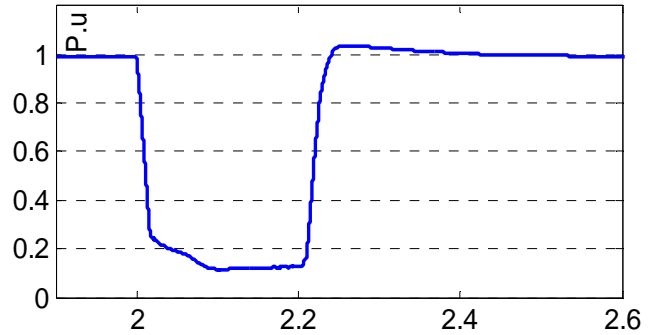

(d)

Figure 26. Response of the DFIG for a grid fault at bus B6 with chopper operation (a) Output active and reactive power of DFIG (b) DC link voltage (c) Chopper current (d) Terminal voltage of the DFIG 


\section{Author details}

Tamer A. Kawady and Ahmed M. Nahhas

Electrical Engineering Department, Umm Al-Qura University, Makkah, Saudi Arabia

\section{References}

[1] Global Wind Energy Council, GWEC, "Global Wind Energy: Annual Market Update 2011", GWEC, 2011, www.gwec.org

[2] Tamer Kawady, Naema Mansour and A. I. Taalab, "Wind Farm Protection Systems: State of the Art and Challenges", a book chapter in "Alternative Energy", edited by D. N. Gaonkar, ISBN 978-953-307-046-9, Intechweb, Vienna, Ostria, 2010.

[3] James F. Manwell, Jon G. McGowan, "Wind Energy Explained: Theory, Design and Application", Wiley; 2 edition (February 9, 2010)

[4] Tony Burton (Author), Nick Jenkins (Author), David Sharpe (Author), Ervin Bossanyi (Author), Wind Energy Handbook, Wiley; 2 edition (June 21, 2011)

[5] Siegfried Heier (Author), Rachel Waddington (Translator), "Grid Integration of Wind Energy Conversion Systems", Wiley; 2 edition (June 5, 2006).

[6] Thomas Ackermann, "Wind Power in Power Systems", Wiley; 2 edition (May 29, 2012).

[7] Mohd. Hasan Ali, "Wind Energy Systems: Solutions for Power Quality and Stabilization ", CRC Press; 1 edition (February 16, 2012).

[8] Jan Machowski, Janusz W. Bialek, James R. Bumby, " Power System Dynamics: Stability and Control", 2008, Second Edition, John Wiely and Sons, LTD.

[9] P.Vijayan and S.Sarkar, and V. Ajjarapu, "A Novel Voltage Stability Assessment Tool to Incorporate Wind Variability", Power \& Energy Society General Meeting, 2009. PES '09. IEEE 26-30 July 2009.

[10] Mohsen Rahimi, Mostafa Parniani, "Dynamic behavior and transient stability analysis of fixed speed wind turbines", Renewable Energy 34 (2009) 2613-2624

[11] F. Wua, X.-P. Zhangb, P. Jua, "Small signal stability analysis and control of the wind turbine with the direct-drive permanent magnet generator integrated to the grid", Electric Power Systems Research 79 (2009) 1661-1667.

[12] Libao Shi, Shiqiang. Dai, Yixin Ni, Liangzhong Yao, and Masoud Bazargan, "Transient Stability of Power Systems with High Penetration of DFIG Based Wind Farms", Power \& Energy Society General Meeting, 2009. PES '09. IEEE 26-30 July 2009. 
[13] Tamer Kawady, Hassan Shaaban and Abdulla El-Said, " Investigation of Grid-Support Capabilities of Doubly Fed Induction Generators During Grid Faults ", accepted for publications in Renewable Power Generation (RPG) - 2011, 6-8 September 2011, Edinburgh, UK.

[14] G. Tsourakisa, B.M. Nomikosb, C.D. Vournasa, "Effect of wind parks with doubly fed asynchronous generators on small-signal stability", Electric Power Systems Research 79 (2009) 190-200.

[15] Durga Gautam, Vijay Vittal, "Impact of DFIG based Wind Turbine Generators on Transient and Small Signal Stability of Power Systems", Power \& Energy Society General Meeting, 2009. PES '09. IEEE 26-30 July, 2009.

[16] Eduard Muljadi, C. P. Butterfield, Brian Parsons, and Abraham Ellis, "Effect of Variable Speed Wind Turbine Generator on Stability of a Weak Grid", IEEE Transactions on Energy Conversion, Vol. 22, No. 1, March 2007.

[17] K. A. Folly and S. P. N. Sheetekela, "Impact of Fixed and Variable Speed Wind Generators on the Transient Stability of a Power System Network", Power Systems Conference and Exposition, 2009. PES '09. IEEE/PES 15-18 March 2009.

[18] Durga Gautam, Vijay Vittal, and Terry Harbour, "Impact of Increased Penetration of DFIG-Based Wind Turbine Generators on Transient and Small Signal Stability of Power Systems, IEEE Transactions on Power Systems, Vol. 24, No. 3, August 2009.

[19] Sherif O. Faried, Roy Billinton, "Probabilistic Evaluation of Transient Stability of a Wind Farm", IEEE Transactions on Energy Conversion, Vol. 24, No. 3, September 2009.

[20] F. Wu, X.-P. Zhang, K. Godfrey and P. Ju, "Small signal stability analysis and optimal control of a wind turbine with doubly fed induction generator", IET Gener. Transm. Distrib., 2007, 1, (5), pp. 751-760.

[21] Eknath Vittal, Andrew Keane, and Mark O'Malley, "Varying Penetration Ratios of Wind Turbine Technologies for Voltage and Frequency Stability", Power and Energy Society General Meeting - Conversion and Delivery of Electrical Energy in the 21st Century, 2008,IEEE, 20-24 July 2008.

[22] H.R. Najafi F.V.P. Robinson, F. Dastyar, A.A. Samadi, "Small-Disturbance Voltage Stability of Distribution Systems with Wind Turbine implemented with WRIG", Powereng 2009, Lisbon, Portugal, March 18-20, 2009

[23] E. Muljadi T. B. Nguyen M.A. Pai, "Impact of Wind Power Plants on Voltage and Transient Stability of Power Systems", IEEE Energy 2030 Atlanta, Georgia, USA, 17-18 November 2008.

[24] Ha Thu Le, Surya Santoso, "Analysis of Voltage Stability and Optimal Wind Power Penetration Limits for a Non-radial Network with an Energy Storage System", Power Engineering Society General Meeting, 2007. IEEE 24-28 June 2007. 
[25] Nayeem Rahmat Ullah, Torböjrn Thiringer, and Daniel Karlsson, "Voltage and Transient Stability Support by Wind Farms Complying With the E.ON Netz Grid Code", IEEE Transactions on Power Systems, Vol. 22, No. 4, November 2007.

[26] Magni P. Pálsson, Trond Toftevaag, Kjetil Uhlen, John Olav Giæver Tande, "Largescale Wind Power Integration and Voltage Stability Limits in Regional Networks", Power Engineering Society Summer Meeting, 2002 IEEE, Volume 2, 25-25 July 2002 Page(s):762 - 769 vol.2.

[27] E. Vittal, A. Keane, and M. O'Malley," Varying Penetration Ratios of Wind Turbine Technologies for Voltage and Frequency Stability", IEEE-2008.

[28] Union for the Co-ordination of Transmission of Electricity (UCTE), "FINAL Report System Disturbance on 4 NovembeR 2006", UCTE, Brussels - Belgium, ww.ucte.org.

[29] Tennis M.W., Clemmer S., and Howland J., Assessing Wind Resources: A Guide for Landowners, Project Developers, and Power Suppliers, Union of Concerned Scientist.

[30] Michael C.B., Patrick H., and Rich S., A GIS Assisted Approach to Wide Area Wind Resource Assessment and Site Selection for the State of Colorado, Presented at Windpower 1996, The Annual Conference and Exhibition of the American wind Energy Association, Denever, Colorado, June 23-27, (1996).

[31] Potts J.R., Pierson S.W., Mathisen P.P., Hamel J.R., and Babau V.C., Wind Energy Assessment of Western and Central Massachusetts, AIAA-2001-0060, 2001.

[32] Srinivas R. Chellapilla and B. H, Chowdhury, "A Dynamic model of Induction Generators for Wind Power Studies", Power Engineering Society General Meeting, 2003, IEEE, Volume 4, 13-17 July 2003, pp. 2340-2344

[33] T. Petru and T. Thiringer, "Modeling of wind turbines for power system studies", Power Systems, IEEE Transactions on

[34] Volume 17, Issue 4, Nov. 2002 Page(s):1132 - 1139.

[35] Krause, P.C., O. Wasynczuk, and S.D. Sudhoff, "Analysis of Electric Machinery", IEEE Press, 1995.

[36] Luis M. Fernandez, Jose Ramo Saenz, Francisco Jurado “Dynamic models of Wind farms with fixed speed wind turbines", Renewable energy 31 (2006), Elsevier, pp. 1203-1230.

[37] ION BOLDEA, Polytechnical Institute Timisoara, R man,"Variable Speed Generators". Published in 2006 by CRC Press Taylor \& Francis Group.

[38] S. K Salman and Babak Badrzadeh School of Engineering, The Robert Gordon University, Schoolhill, Aberdeen, AB10 1FR, Scotland, U.K. "New Approach for modeling Doubly-Fed Induction Generator (DFIG) for grid-connection studies" 
[39] Jaroslav Lepka, Petr Stek, " 3-Phase AC Induction Motor Vector Control Using a 56F80x, 56F8100 or 56F8300 Device Design of Motor Control Application". Freescale Semiconductor Application Note, 2004.

[40] Ekanayake, J.B., Holdsworth, L., Wu, X.G., Jenkins, N. 2003b. “Dynamic Modeling of Doubly Fed Induction Generator Wind Turbines", IEEE Transaction on Power Systems, Vol. 18, Issue 2, May 2003, pp. 803-809.

[41] Anca D. Hansen and Gabriele Michalke, "Voltage grid support of DFIG wind turbines during grid faults", EWEC2007 International Conference.

[42] R. Bena, J. Clare and G. Asher, "Doubly fed induction generator using back-to-back PWM converters and its application to variable speed wind-energy generation", Generation, Transmission and Distribution, IEE Proceedings, Volume 143, Issue 3, May. 1996.

[43] P. Cartwright, L. Holdsworth, J.B. Ekanayake and N. Jenkins, "Coordinated voltage control strategy for a doubly fed induction generator (DFIG)-based wind farm", Generation, Transmission and Distribution, IEE Proceedings, Volume 151, Issue 4, July 1996.

[44] Hansen A.D., Michalke G., Sørensen P., Lund T., Iov F. Co-ordinated voltage control of DFIG wind turbines in uninterrupted operation during grid faults, Wind Energy, No. 10, 2007, pp. 51-68.

[45] Akhmatov V., Variable-speed wind turbines with doubly fed induction generators. Part II: Power System Stability. Wind Engineering, Vol. 26, No. 3, 2002, pp 171-188.

[46] Johan Morren, Jan Pierik and Sjoerd W.H. Haan, "Inertial response of variable speed wind turbines", Electric Power Systems Research, 76 (2006), pp. 980-987.

[47] A. Tapia, G. Tapia, J.X. Ostolaza, "Reactive power control of windfarms for voltage control applications", Renewable Energy, 29 (2004), pp. 377-392.

[48] Zhang Yong, Duan Zhengang, Liu Xuelian, "Comparison of Grid Code Requirements with Wind Turbine in China and Europe", Power and Energy Engineering Conference (APPEEC), 2010 Asia-Pacific, 28-31 March 2010.

[49] I. Erlich, M. Wilch and C. Feltes, "Reactive Power Generation by DFIG Based Wind Farms with AC Grid Connection", Power Tech 2007, IEEE Lausanne, 1-5 July 2007.

[50] I. Erlich, U. Bachmann, "Grid Code Requirements Concerning Connection and Operation of Wind Turbines in Germany", IEEE Power Engineering Society General Meeting, 2005.

[51] Choudhury S., Mohanty K.B., Debta B.K., "Investigation on performance of Doublyfed induction generator driven by wind turbine under grid voltage fluctuation", Environment and Electrical Engineering (EEEIC), 2011 10th International Conference. 
[52] I. Erlich, H. Wrede, and C. Feltes,"Dynamic Behavior of DFIG-Based Wind Turbines during Grid Faults", Power Conversion Conference - Nagoya, 2007. PCC '07.

[53] Tamer Kawady, N. Mansour, A. Osheiba, A. E. Taalab and R. Ramakumar, "Modeling and Simulation aspects of wind farms for protection applications," Proceedings of 40th Annual Frontiers of Power Conference, Oklahoma State University, Stillwater, October 29-30, 2007, pp X-1 to X-7.

[54] Tamer Kawady, "An Interactive Simulation of Grid-Connected DFIG Units for Protective Relaying Studies", IEEE PES/IAS Sustainable Alternative Energy Conference-2009, Valencia, Spain, 28-30 Sept., 2009.

[55] Ekanayake, J.B., Holdsworth, L., Wu, X.G., Jenkins, N. 2003b. "Dynamic Modeling of Doubly Fed Induction Generator Wind Turbines", IEEE Transaction on Power Systems, Vol. 18, Issue 2, May 2003, pp. 803-809.

[56] Anca D. Hansen and Gabriele Michalke, "Voltage grid support of DFIG wind turbines during grid faults", EWEC2007 International Conference.

[57] I. Erlich, M. Wilch and C. Feltes, "Reactive Power Generation by DFIG Based Wind Farms with AC Grid Connection", Power Tech 2007, IEEE Lausanne, 1-5 July 2007.

[58] I. Erlich, U. Bachmann, "Grid Code Requirements Concerning Connection and Operation of Wind Turbines in Germany", IEEE Power Engineering Society General Meeting, 2005.

[59] I. Erlich, W. Winter, A. Dittric, "Advanced Grid Requirements for the Integration of Wind Turbines into the German Transmission System", Power Engineering Society General Meeting, 18-22 June 2006, Montreal, Canada.

[60] Tamer Kawady, N. Mansour, A. Osheiba, and A. I. Taalab, " Detailed Modeling and Control of DFIG Units for Large Wind Farms Using MATLAB ", Middle East Power System Conf. (MEPCON 2009), 20-23 Dec., 2009, Assuit, Egypt.

[61] Wilch, M.; Pappala, V.S.; Singh, S.N. \& Erlich, I., " Reactive Power Generation by DFIG Based Wind Farms with AC Grid Connection", IEEE Powertech 2007, 1-5 July 2007, Lausanne, Switzerland, pp. 626-632.

[62] Hassan Shaaban, Tamer Kawady and Abdulla Elsherif, "Transient Stability studies of Power Systems with High Penetration of FSIG-Based Wind farms", Engineering Journal of Minoufiya University, Shebin El-Kom, Egypt.

[63] Istvan Erlich, Jörg Kretschmann, Jens Fortmann, Stephan Mueller-Engelhardt, and Holger Wrede, " Modeling of Wind Turbines Based on Doubly-Fed Induction Generators for Power System Stability Studies", IEEE Transactions on Power Systems, Vol. 22, No. 3, August 2007, pp. 909-919. 
[64] K.E. Okedu, S. M. Muyeen, R. Takahashi and J. Tamura, “Wind Farms Fault Ride Through using DFIG with New Protection Scheme", IEEE Trans. on Sustainable Energy, Vol. 3, No. 2, pp. 242 - 254, 2012.

[65] Tamer Kawady, Hassan Shaaban and Abdulla El-Said, " Investigation of Grid-Support Capabilities of Doubly Fed Induction Generators During Grid Faults ", accepted for publications in Renewable Power Generation (RPG) - 2011, 6-8 September 2011, Edinburgh, UK.

[66] P. M. Anderson and A. A. Fouad, "Power System Control and Stability", Text Book, John Wiley and Sons, New York, 2003.

[67] S.M. Muyeen, Junji Tamura and Toshiaki Murata, " stability augmentation of a grid connected wind farm", Text Book, Springer-Verlag London Limited, 2009. 
